Universidade de São Paulo

Escola Superior de Agricultura "Luiz de Queiroz"

L-prolina no alívio do estresse térmico em tomateiro cultivado em ambiente protegido

\title{
Rachel Tonhati
}

Dissertação apresentada para obtenção do título de Mestra em Ciências. Área de concentração: Fitotecnia 
Rachel Tonhati

Bacharel em Engenharia Agronômica

L-prolina no alívio do estresse térmico em tomateiro cultivado em ambiente protegido

Orientadora:

Prof. Dra. SIMONE DA COSTA MELLO

Dissertação apresentada para obtenção do título de

Mestra em Ciências. Área de concentração: Fitotecnia 

Dados Internacionais de Catalogação na Publicação
DIVISÃO DE BIBLIOTECA - DIBD/ESALQ/USP

Tonhati, Rachel

L-prolina no alívio do estresse térmico em tomateiro cultivado em ambiente protegido / Rachel Tonhati. - - Piracicaba, 2018.

$50 \mathrm{p}$.

Dissertação (Mestrado) - - USP / Escola Superior de Agricultura "Luiz de Queiroz".

1. Estresse oxidativo 2. Altas temperaturas 3. Aminoácidos 4. Estresse abiótico I. Título 
DEDICATÓRIA

Dedico aos meus pais pela extrema dedicação em minha formação e pelo constante apoio. 


\section{AGRADECIMENTOS}

Aos meus pais, por todo o suporte em minhas decisões e constante dedicação a minha formação.

À Simone da Costa Mello, minha orientadora, por todo apoio na realização da pesquisa, ensinamentos e orientação.

Ao professor Ricardo Antunes de Azevedo, pela disponibilização do laboratório para realização de análises.

À Salete Gaziola, pelo auxílio constante nas realizações de todas análises bioquímicas.

Ao professor de estatística Marcelo Corrêa Alves, pelo auxílio e ensinamentos nas análises de dados.

À Silvia Lourenço, pelo auxílio nas avaliações com o IRGA.

Aos funcionários do Departamento de Produção Vegetal, pela ajuda na condução dos experimentos.

A todos integrantes e ex-integrantes do grupo GEPOL, por toda transferência de conhecimentos, auxílio no desenvolvimento dos experimentos e também pelos momentos de descontração.

Ao meu namorado Marcelo, pelo apoio e compreensão em todas os momentos e decisões durante a realização do mestrado.

Aos amigos que a pós-graduação me deu, Thaís, Isabela, Fábio, Alessandro, Antônio, Fernando, Gustavo, Rafael, Pedro Rony, Mayara, Bia, Ricardo, Yane, Matheus, Renata, Rafaela, Kelly, Mariana, Lígia, Guilherme.

Às amigas mais antigas, estreitando ainda mais a amizade, Larissa e Suzana, pelo apoio em todas as horas e muitos almoços.

Às meninas da República Atentado, por todos os anos de estreita convivência, por sempre me ajudarem no que foi preciso, serem minha família e minha casa, e por todos os inesquecíveis momentos vividos.

À empresa Ajinomoto do Brasil, por fornecer o apoio técnico e financeiro sem o qual não seria possível realizar esta pesquisa.

Ao CNPQ, pelo auxílio financeiro na concessão da bolsa de estudos para realização da pesquisa.

E a todos os envolvidos direta e indiretamente, meu muito obrigada! 
SUMÁRIO

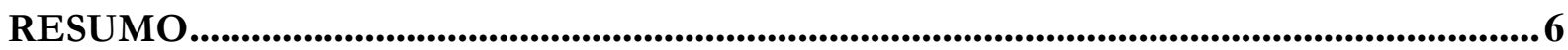

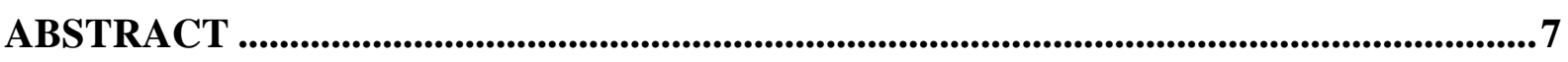

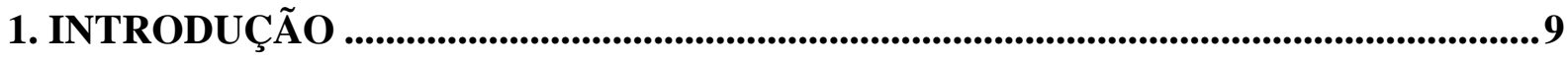

2. REVISÃO BIBLIOGRÁFICA ….................................................................................11

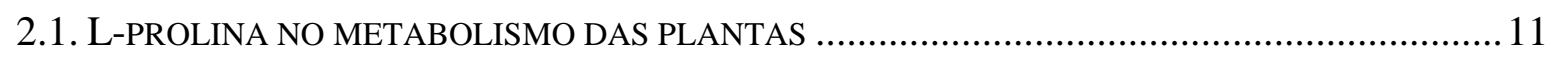

2.2. L-PROLINA, ESTRESSE E FOTOSSÍNTESE............................................................ 14

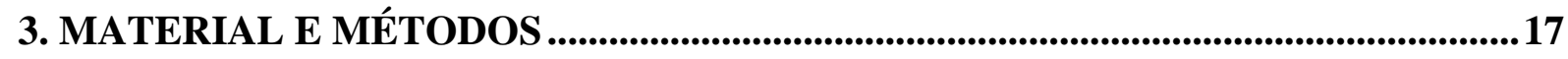

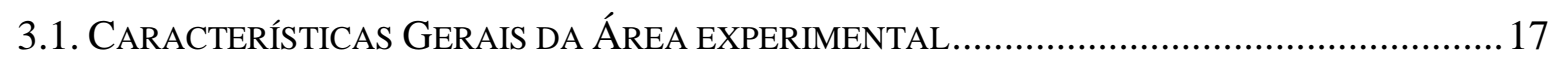

3.2. TRATAMENTOS E DELINEAMENTO EXPERIMENTAL .................................................... 17

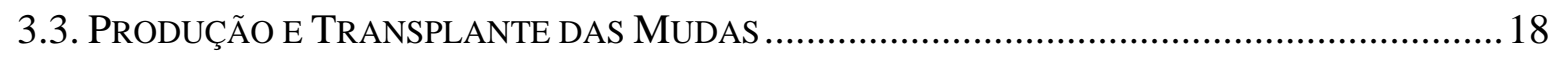

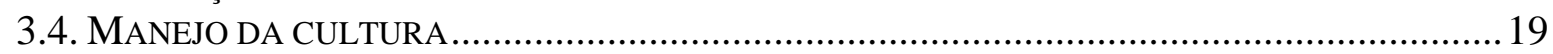

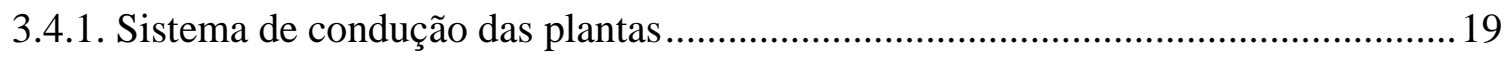

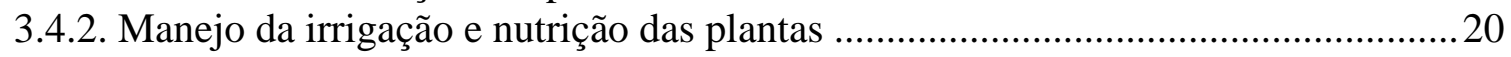

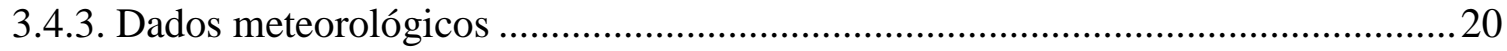

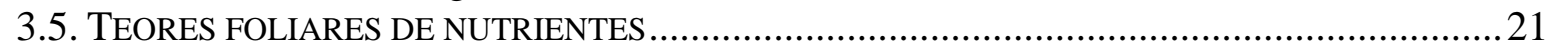

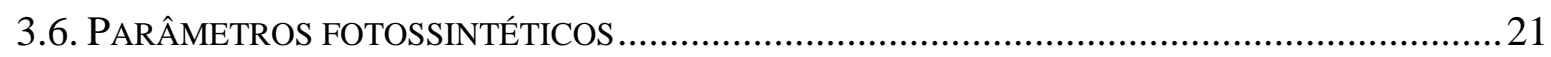

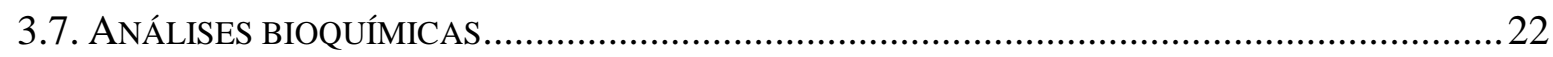

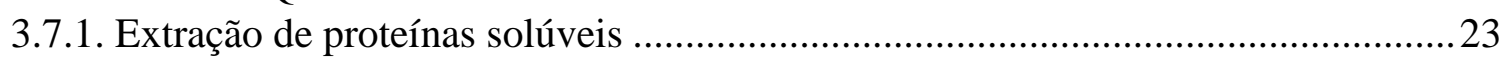

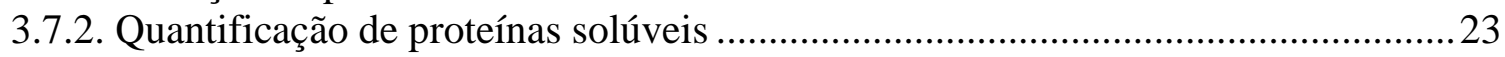

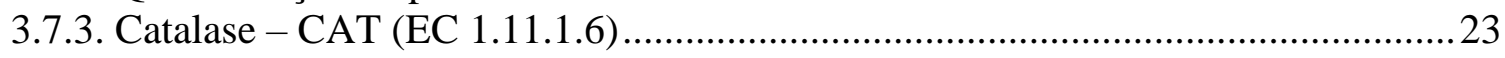

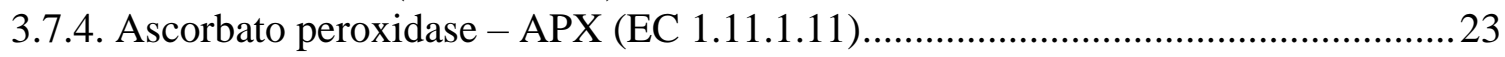

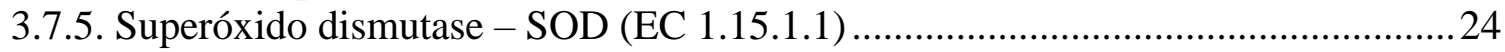

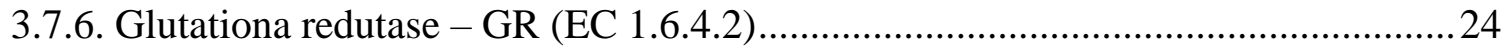

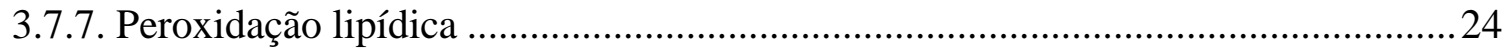

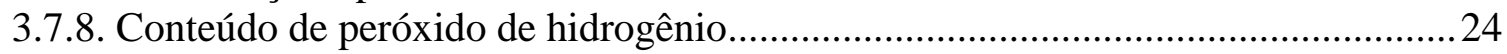

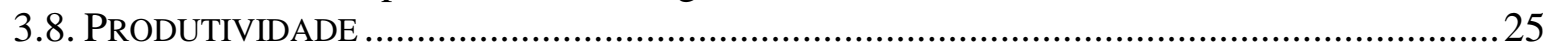

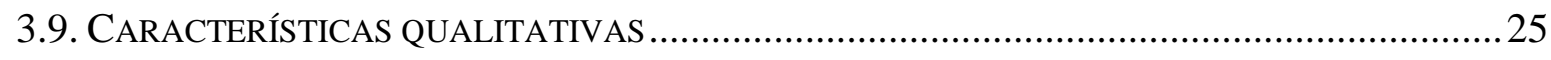

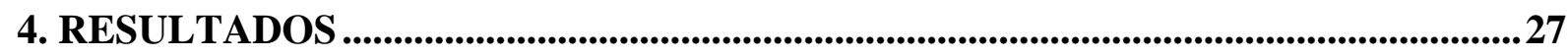

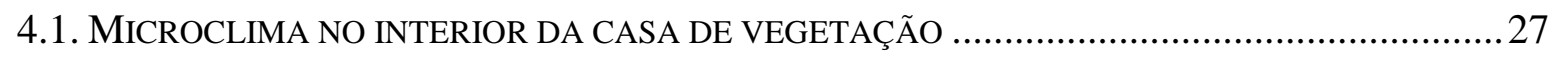

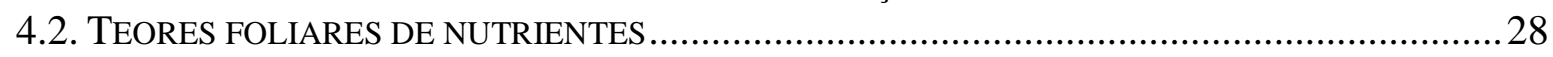

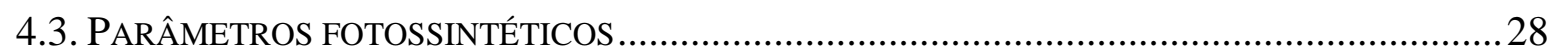

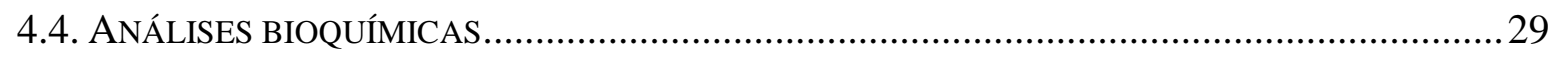

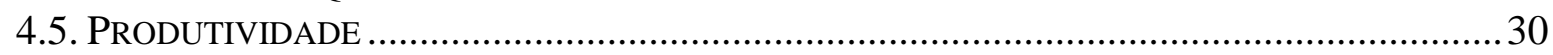

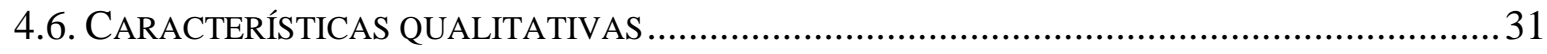

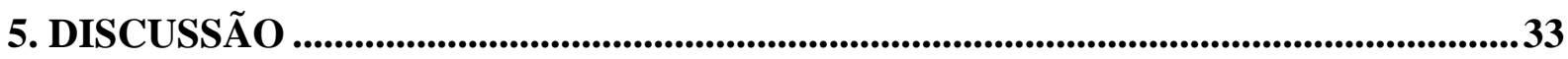

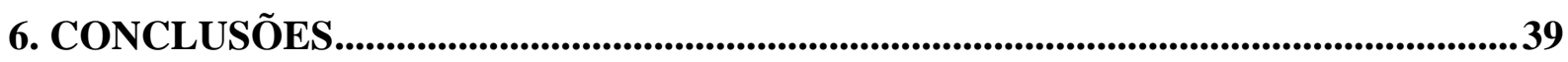

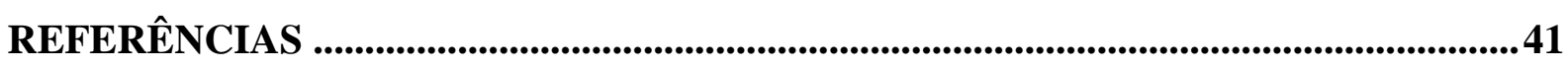




\section{RESUMO}

\section{L-prolina no alívio do estresse térmico em tomateiro cultivado em ambiente protegido}

A produção de tomate (Solanum lycopersicum L.) no estado de São Paulo é de grande importância para a produção brasileira, pois representa $21,5 \%$ da produção total e é o principal estado produtor de tomate de mesa. O tomate de mesa é cultivado por tutoramento das plantas e o cultivo em casas de vegetação é uma prática crescente no Brasil, trazendo muitas vantagens a produção, como proteção às chuvas e pragas. Porém em muitos casos, dependendo da estrutura utilizada, pode ocorrer aumento da temperatura interna das casas de vegetação. O tomateiro é uma planta sensível as altas temperaturas, e alterações dos níveis ótimos podem causar danos no metabolismo e consequentemente na produtividade da cultura. Altas temperaturas no cultivo de tomate são prejudiciais ao seu desenvolvimento, pois alteram a homeostase celular e desregulam funções vitais das plantas, como fotossíntese, gerando em excesso espécies reativas de oxigênio (EROs) como os radicais superóxidos, peróxido de hidrogênio e radicais hidroxilas, que são tóxicos às plantas e causam estresse oxidativo, levando até a sua morte. Plantas estressadas acumulam solutos osmoprotetores, entre eles a Lprolina, que auxiliam na proteção das estruturas celulares, na eliminação das EROs e também ativam o metabolismo antioxidante das plantas. Além da acumulação endógena de L-prolina, a aplicação exógena desse aminoácido pode trazer vantagens ao alívio do estresse térmico. Esse estudo teve por objetivo avaliar a eficiência da L-prolina nas doses de 0, 50, 100, 200, 400, 800 e 1600 $\mathrm{mg} / \mathrm{L}$ na nutrição foliar, parâmetros fotossintéticos, enzimas do sistema antioxidante, malonaldeído e peróxido de hidrogênio, produtividade e características pós colheita dos frutos. Os dados climáticos durante o cultivo do tomateiro evidenciaram a ocorrência de temperaturas elevadas durante o ciclo de produção. Assim, foi possível observar que a aplicação exógena de L-prolina nas doses de 50 e 100 mg/L aumentaram a eficiência do uso da água, diminuíram o conteúdo de malonaldeído e aumentaram a produtividade comercial e total de frutos por planta. O uso de $50 \mathrm{mg} / \mathrm{L}$ desse aminoácido também proporcionou aumento do número de frutos comerciais por planta. A aplicação de L-prolina, independente da dose, proporcionou diminuição no conteúdo de peróxido de hidrogênio e elevou a atividade das enzimas do sistema antioxidante, além de melhorar a qualidade do fruto, diminuindo a acidez e aumentando a relação SST/ATT. Dessa maneira, constatou-se o efeito positivo do uso exógeno da Lprolina no alívio dos danos causados por altas temperaturas, principalmente em plantas tratadas com 50 e $100 \mathrm{mg} / \mathrm{L}$.

Palavras-chave: Estresse oxidativo; Altas temperaturas; Aminoácidos; Estresse abiótico 


\section{ABSTRACT \\ L-prolina no alívio do estresse térmico em tomateiro cultivado em ambiente protegido}

The production of tomato (Solanum lycopersicum L.) in the state of São Paulo is of great importance for the Brazilian production, it represents $21.5 \%$ of total production and is the main state table tomato producer. The fresh tomato is grown by staking of plants and cultivation in greenhouses is a growing practice in Brazil, bringing many benefits to production, as protection of rain and pests. However, in many cases, depending on the structure used, there may be an increase in the internal temperature of the greenhouse. The tomato is a plant sensitive to high temperatures, and changes in optimal levels can cause damage to metabolism and consequently crop productivity. High temperatures in tomato cultivation are detrimental to their development, as they alter cellular homeostasis and deregulate vital plant functions, such as photosynthesis, generating in excess reactive oxygen species (ROS) such as superoxide radicals, hydrogen peroxide and hydroxyl radicals, which are toxic to plants and cause oxidative stress, leading to their death. Stressed plants accumulate osmoprotective solutes, including proline, which help protect cell structures, eliminate ROS and also activate plant antioxidant metabolism. In addition to the accumulation of endogenous proline, exogenous application of this amino acid can bring advantages to the relief of heat stress. The objective of this study was to evaluate the efficiency of L-proline at doses of 0, 50, 100, 200, 400, 800 and 1600 $\mathrm{mg} / \mathrm{L}$ by foliar spray, in photosynthetic parameters, antioxidant system enzymes, malonaldehyde and hydrogen peroxide, productivity and post-harvest characteristics of fruits. The climatic data during tomato cultivation evidenced the occurrence of high temperatures during the production cycle. Thus, it was possible to observe that the exogenous application of L-proline at doses of 50 and $100 \mathrm{mg} / \mathrm{L}$ increased the efficiency of water use, decreased malonaldehyde content and increased commercial and total fruit yield per plant. The use of $50 \mathrm{mg}$ / $\mathrm{L}$ of this amino acid also provided an increase in the number of commercial fruits per plant. The application of L-proline, regardless of the dose, resulted in a decrease in the hydrogen peroxide content and increased the activity of the antioxidant system enzymes, besides improving fruit quality, decreasing the acidity and increasing the SST/ATT ratio. Thus, there was the positive effect of the exogenous use of L-proline in alleviating the damage caused by high temperatures, especially in plants treated with 50 and $100 \mathrm{mg} / \mathrm{L}$.

Keywords: Oxidative stress; High temperatures; Amino acids; Abiotic stress 


\section{INTRODUÇÃO}

O tomate (Solanum lycopersicum L.) é uma das hortaliças de destaque na produção mundial e brasileira, possuindo grande importância social e econômica. O Brasil se encontra entre os dez principais produtores de tomate no mundo, e sua produção em 2017 foi de 4.373 .047 toneladas em uma área de 64 mil hectares, com produtividade média de 67,64 t/ha. O estado de São Paulo representa 21,50 \% da produção nacional (938.800 t), sendo que 75\% se deve ao cultivo de tomate de mesa, ocupando 12 mil hectares (IBGE, 2018).

O manejo da cultura depende das condições ambientais, as quais afetam a fisiologia, crescimento e produtividade do tomateiro (ALVARENGA, 2013). Essa espécie é cultivada principalmente em campo, mas o cultivo em ambiente protegido vem aumentando por possibilitar o controle dos fatores ambientais e aumento da eficiência do uso de recursos naturais e insumos, garantindo aumento de produtividade e qualidade. Porém, o cultivo protegido no Brasil é realizado, na sua maioria, em casa de vegetação não climatizada porque o controle total do clima exige elevado investimento inicial e manutenção durante o processo produtivo. Nessa condição, as temperaturas no interior do ambiente protegido têm sido mais elevadas, gerando em vários sistemas de cultivo estresses ao desenvolvimento e produção do tomateiro.

O tomate é uma cultura sensível ao estresse térmico, onde as temperaturas ótimas para a germinação estão entre 15 e $25^{\circ} \mathrm{C}$, para formação de mudas entre 20 e $25^{\circ} \mathrm{C}$, florescimento entre $1824^{\circ} \mathrm{C}$, pegamento de frutos entre 14 e $17^{\circ} \mathrm{C}$ no período noturno e 19 e $24^{\circ} \mathrm{C}$ diurno, e na fase de maturação entre 20 e $24^{\circ} \mathrm{C}$ (ALVARENGA, 2013).

O estresse por aquecimento é muito comum em plantas, variando conforme a sucessão das estações e, em algumas situações, durante o dia. A intensidade, o período e a duração do estresse provocado pela temperatura podem provocar alterações celulares e metabólicas, induzindo as plantas a adquirir tolerância a situações adversas (SUNG et al., 2003). Porem a resposta do tomateiro depende também da tolerância de cada material genético ao excesso de calor.

O estresse por aquecimento altera a homeostase celular e, quando severo, pode conduzir ao atraso do crescimento e desenvolvimento vegetal, acelerar a maturidade fisiológica e até mesmo causar a morte celular, o que no cenário agrícola pode significar perdas expressivas de produção (NAGARAJAN; NAGARAJAN, 2010). Estes danos são causados pela redução do fluxo de íons e a inibição da fotossíntese, resultando no aumento excessivo na produção substâncias tóxicas como os radicais superóxidos $\left(\mathrm{O}_{2}{ }^{-}\right)$, peróxido de hidrogênio $\left(\mathrm{H}_{2} \mathrm{O}_{2}\right)$ e radicais hidroxilas $\left(\mathrm{OH}^{-}\right)$, como resultado do desequilíbrio entre as etapas fotoquímicas e bioquímicas, o que é responsável 
por grande parte da morte celular durante as condições de estresse (KIM et al., 2009; SOLIMAN et al., 2012; WAHID et al., 2007).

Um mecanismo de resposta ao estresse em plantas é o acúmulo de solutos osmoprotetores, tais como a L-prolina (CLAUSSEN, 2005; RIVERO; RUIZ; ROMERO, 2004). A L-prolina é importante indicador de resposta ao estresse, uma vez que protege as estruturas de proteínas da desnaturação, estabiliza as membranas celulares por interações com fosfolipídios, combate radicais hidroxilas e pode ser usada como fonte de energia e de N (CLAUSSEN, 2005). A Lprolina tem efeito de estabilização do complexo II da cadeia de transporte de elétrons, membranas de proteínas e enzimas como a RUBISCO (ALLEN et al., 1997; HAMILTON, 2001; MÄKELÄ et al., 2000), e dessa maneira, age como protetor do aparato fotossintético das plantas em condições de estresses. Em estudo realizado por Bem Ahmed et al. (2010), o uso de L-prolina exógena suprimiu a redução da atividade fotossintética sob estresse salino.

Dessa maneira, em situações de estresse, geralmente a concentração de L-prolina é aumentada na planta. Esse aminoácido, não somente mantem a pressão de turgor da célula, como também protege as enzimas e as moléculas da oxidação por espécies reativas de oxigênio (EROs) (FAROOQ et al., 2009).

Além da L-prolina endógena, a aplicação desse aminoácido tem sido realizada por pulverizações foliares ou através da fertirrigação, para absorção pelas raízes. Segundo Hayat et al. (2012), a aplicação exógena de L-prolina em condições de estresses por elevadas temperaturas, salinidade e por metais pesados, eliminou as EROs, manteve a turgidez celular e elevou a taxa fotossintética de plantas. Taiz et al. (2017) citam que o acumulo de solutos osmoprotetores nas plantas, acarreta em perda de produção, visto que há gasto energético, portanto a aplicação exógena de pode aumentar o conteúdo de L-prolina na planta sem gasto energético.

Essa pesquisa teve por objetivo avaliar a aplicação exógena de L-prolina na fisiologia, desenvolvimento, produtividade e qualidade do tomateiro em ambiente protegido. 


\section{REVISÃO BIBLIOGRÁFICA}

\subsection{L-prolina no metabolismo das plantas}

Os aminoácidos são compostos intermediários da síntese dos hormônios vegetais, que também podem ter função de promoção de resistência ao estresse hídrico e de altas temperaturas, além de maior tolerância ao ataque de pragas e doenças (CASTRO; CARVALHO, 2014). Esses autores observaram que os aminoácidos são compostos anti-estressantes que são capazes de agir em processos morfológicos e fisiológicos das plantas como precursores de hormônios e enzimas. Entretanto, segundo outros autores, a utilização de aminoácidos em diversas culturas não tem o objetivo de suprir a necessidade para a síntese proteica, mas sim, de ativar o metabolismo fisiológico das plantas, sendo precursores de hormônios vegetais, compostos fenólicos (que atuam na defesa das plantas) e da síntese de clorofila, podendo assim ter uma ação contra o estresse, agindo também no metabolismo secundário. Dentre os aminoácidos utilizados para alívio do efeito do estresse encontra-se a L-prolina.

A L-prolina é considerada um dos vinte aminoácidos presentes nas proteínas de todos os organismos vivos, sendo essencial nos metabolismo primário (MOLINARI, 2006; SZABADOS; SAVOURÉ, 2010). Possui fórmula química $\mathrm{C}_{5} \mathrm{H}_{9} \mathrm{NO}_{2}$ e massa molecular de $115,13 \mathrm{~g} / \mathrm{mol}$. Sua síntese é dada a partir do glutamato, que é reduzido em 2 reações pela enzima pirrolina-5carboxilato sintase (P5CS) a glutamato-semialdeído (GSA) e pela enzima P5C redutase (P5CR) até L-prolina. O processo da síntese da L-prolina ocorre no citosol em condições normais e nos cloroplastos, quando ocorrem situações de estresse, a maior parte dos estudos foi comprovada em Arabidopsis, porém são válidos para outras espécies (SZABADOS; SAVOURÉ, 2010). Como via alternativa de síntese de L-prolina, existe a via da ornitina, onde a mesma é transaminada pela enzima ornithine-delta-aminotransferase (OAT), formando GSA e PC5 que é reduzido à Lprolina, sendo parte da síntese ocorrida na mitocôndria, com o uso da arginina como substrato. O processo de catabolismo da L-prolina ocorre preferencialmente nas mitocôndrias onde o produto final é o glutamato (SZABADOS; SAVOURÉ, 2010). O ciclo P5C-prolina pode fornecer elétrons ao transporte de elétrons mitocondriais sem produzir glutamato e, sob certas condições, pode gerar mais EROs nas mitocôndrias (MILLER et al., 2009). O catabolismo da Lprolina é, portanto, um importante regulador do equilíbrio das EROs celulares e pode influenciar várias vias regulatórias adicionais.

É sugerido que a via da ornitina é mais importante durante o desenvolvimento inicial das plântulas, e também em plantas sob stress induzindo na acumulação de L-prolina (ARMENGAUD et al., 2004; 1998; XUE; LIU; HUA, 2009). Em plantas de lavanda, a L-prolina 
foi sequestrada nos vacúolos em plantas não estressadas, enquanto em plantas em ambiente salino um alto conteúdo de L-prolina foi detectado no citosol, sugerindo a importância da biossíntese de L-prolina, bem como seu transporte para acumulação (GAGNEUL et al., 2007).

Durante o desenvolvimento, as plantas estão sujeitas a estresses bióticos e abióticos, como variações de temperatura, salinidade, deficiência hídrica e toxidade por metais pesados (HAYAT et al., 2012). Esses fatores quando em situações extremas podem reduzir o desenvolvimento e a produtividade das plantas em diferentes graus, dependendo da severidade do estresse causado. Esses estreses causados por fatores abióticos, causam produção de espécies reativas de oxigênio (EROs), que são tóxicas as plantas, acima da concentração normal, causando danos às células como oxidação das membranas, degradação de organelas e morte celular, gerando o chamado estresse oxidativo (TAIZ et al., 2017). As EROs são altamente reativas e induzem danos aos DNA, RNA, pigmentos, proteínas e lipídios (ASHRAF, 2009). São produzidas naturalmente nas células como um subproduto de várias reações do metabolismo (FOYER; HARBINSON, 1994), desempenhando um importante papel na proteção contra agentes danosos e também em processos do desenvolvimento das plantas (BOLWELL et al., 2002; JACOBSON, 1996) e, são eliminadas por compostos antioxidantes (ALSCHER; DONAHUE; CRAMER, 1997). As EROs são encontradas com maior frequência nas células vegetais nas formas de radicais superóxidos $\left(\mathrm{O}_{2}{ }^{-}\right)$, peróxido de hidrogênio $\left(\mathrm{H}_{2} \mathrm{O}_{2}\right)$ e radicais hidroxilas $\left(\mathrm{OH}^{-}\right)$(TAIZ et al., 2017). Dessa maneira, os níveis de EROs devem ser mantidos dentro dos limites normais para as plantas, tanto em condições normais, quanto em situações de estresses.

Como mecanismo de defesa interna, as plantas possuem diferentes mecanismos para manter os níveis das EROs em condições normais, sendo as mesmas eliminadas por compostos de baixo peso molecular, como metabólitos antioxidantes como, a glutationa reduzida, o ácido ascórbico (vitamina C), $\alpha$-tocoferol (vitamina E) e $\beta$-caroteno (vitamina A) (TAIZ et al., 2017), e também por enzimas antioxidantes como a catalase (CAT), superóxido dismutase (SOD) e ascorbato peroxidase (APX). Porém, em condições de estresse oxidativo, onde a quantidade de radicais livres gerados ultrapassa o poder antioxidativo presentes nas células, ocorrem efeitos adversos ao desenvolvimento das plantas (HAYAT et al., 2012).

Os compostos antioxidantes precisam estar no estado reduzido para desempenhar a correta função nas plantas, que dessa maneira aceita os elétrons das EROs e assim as neutralizam. E para isso, as células utilizam o poder redutor do NADH ou NADPH, produzidos pela respiração ou fotossíntese, para a correta função das redutases glutationa redutase, desidroascorbato redutase e monodesidroascorbato redutase (TAIZ et al., 2017). As enzimas do sistema antioxidante, elencadas por Taiz et al. (2017), atuam no aumento da eficiência do sistema de inativação das 
EROs celulares da seguinte maneira: a SOD oxida e reduz o ânion superóxido produzindo peróxido de hidrogênio e oxigênio $\left(\mathrm{O}_{2}^{-}+2 \mathrm{H}^{+} \rightarrow \mathrm{O}_{2}+\mathrm{H}_{2} \mathrm{O}_{2}\right)$; a APX reduz o peróxido de hidrogênio à agua utilizando o ácido ascórbico ( 2 L-ascorbato $+\mathrm{H}_{2} \mathrm{O}_{2}+2 \mathrm{H}^{+} \rightarrow 2$ monodesidroascorbato $+2 \mathrm{H}_{2} \mathrm{O}$ ); a CAT decompõe o peróxido de hidrogênio em água e oxigênio ( $2 \mathrm{H}_{2} \mathrm{O}_{2} \rightarrow 2 \mathrm{H}_{2} \mathrm{O}+\mathrm{O}_{2}$ ); por fim, os íons hidroxila e oxigênio singleto são metabolizados pela rota da glutationa (TAIZ et al., 2017).

Como resposta ao estresse oxidativo, as plantas acumulam grandes quantidades de solutos osmoprotetores, que possuem baixo peso molecular, altamente solúveis e não tóxicos às células em altas concentrações. Esses compostos ajudam na proteção das células contra os estresses, atuando no ajuste osmótico, na eliminação das EROs, na proteção da membrana celular e também na proteção e estabilização das enzimas (ASHRAF; FOOLAD, 2007). Dentre esses compostos está a L-prolina, que protege as proteínas da desnaturação, estabiliza as membranas celulares por interações com fosfolipídios, combate radicais hidroxilas e pode ser usada como fonte de energia e de N (CLAUSSEN, 2005). A L-prolina, não somente mantem a pressão de turgor da célula, como também protege as enzimas e as moléculas da oxidação por espécies reativas de oxigênio (FAROOQ et al., 2009). Hong et al. (2000) cita a eliminação de radicais livres como função mais crucial da L-prolina do que seu potencial como soluto osmoprotetor. A síntese dos solutos osmoprotetores é um processo ativo, que gasta energia das células, por isso, em muitos casos onde ocorre a acumulação desses solutos ocorre a perda de produtividade (TAIZ et al., 2017). A acumulação de L-prolina foi verificada em diversas situações, como em estudos realizados por Saradhi; Alia \& Prasad (1995) em plantas de arroz e mostarda submetidas a condições de estresse por radiação UV, por Yang; Lan \& Gong (2009) em plantas de milho sob estresse oxidativo por peróxido de hidrogênio, por Ashraf; Saeed \& Qureshi (1994) em algodoeiro cultivado em altas temperaturas, por Rivero; Ruiz \& Romero (2004) em plantas de tomates sob estresse por altas e baixas temperaturas, por Medeiros et al. (2012) em plantas de acerola sob estresse hídrico severo, por Fumis \& Pedras (2002) em plantas de trigo sob dois regimes de estresse hídrico, por Hong et al. (2000) em células transgênicas de tabaco sob solução salina, e por Naidu et al. (1991) em plantas de trigo sob estresse por baixas temperaturas.

Segundo Szabados \& Savouré (2010), estudos recentes sobre a L-prolina destacam a diversidade de funções que a mesma possui na adaptação, recuperação e sinalização do estresse. A proteção do aparato fotossintético, estabilização de proteínas no cloroplasto e citosol e proteção das enzimas envolvidas no processo de eliminação das EROs são as funções mais importantes do acúmulo da L-prolina em condições de estresse, porém não são as únicas. $\mathrm{O}$ aumento da biossíntese de L-prolina nos cloroplastos, sinalizado em condições de estresse, 
contribui para a manutenção da homeostase celular e do equilíbrio redox, fazendo a dissipação do excesso do potencial de redução ocorrido com a saturação do transporte de elétrons. A ocorrência do catabolismo da L-prolina é relacionado à respiração oxidativa que administra energia para o crescimento ocorrer após a condição de estresse e essa oxidação, ajuda a regular os níveis de EROs nas mitocôndrias. Hare e Cress (1997) também verificaram que a L-prolina aliviou a acidose citoplasmática e manteve a relação NADP +/ NADPH em condições adequadas e compatíveis com o metabolismo das plantas.

Segundo Hoque (2008), Islam (2009) e Khedr (2003) a L-prolina aumentou a atividade das enzimas de desintoxicação, como a peroxidase, superóxido dismutase e catalase, além de as estabilizar diante condições de estresse. A L-prolina é capaz de manter a integridade das proteínas e melhora a ação de diversas enzimas (RAJENDRAKUMAR; SURYANARAYANA; REDDY, 1997). Hayat (2012) propõe também que a acumulação de L-prolina possa ser um sinalizador de estresse que desencadeia respostas adaptativas nas plantas.

\subsection{L-prolina, estresse e fotossíntese}

Um dos componentes mais importantes para o desenvolvimento das plantas é a fotossíntese, porém ela pode ser influenciada por diversos fatores bióticos e abióticos, como intensidade luminosa, variações de temperatura, ataque de pragas e ocorrência de doenças (TAIZ et al., 2017). A fotossíntese é limitada por altas temperaturas, sendo seu nível máximo atingido por volta dos $30^{\circ} \mathrm{C}$, e cada grau acima sinaliza declínios significativos na taxa fotossintética (WISE et al., 2004). Estimativas já mensuraram que a cada grau de elevado na temperatura média no ciclo de desenvolvimento ótimo, pode ocorrer perdas de rendimento de até 17\% (LOBELL; WOSCHLENKER; COSTA-ROBERTS, 2011). Altas temperaturas diminuem a taxa fotossintética líquida, pois afetam negativamente a reação fotoquímica na fase luminosa e reduz a ação da ribulose-1,5-bisfosfato carboxilase-oxigenase (Rubisco) na fase escura da fotossíntese (SALVUCCI; CRAFTS-BRANDNER, 2004; YAMORI et al., 2012). O fotossistema II (PSII) é outro componente sensível ao excesso de calor no aparelho fotossintético. O estresse térmico prejudica o complexo envolvendo o oxigênio do PSII e prejudica a transferência de elétrons nos centros de reação do PSII (KOURIL et al., 2004).

Altas temperaturas desencadeiam uma série de reações que sinalizam o estresse, dessa maneira a fotossíntese é suprimida principalmente pelo fechamento estomático (BEN AHMED; BEN ROUINA; BOUKHRIS, 2007). Com a ocorrência do aumento do estresse a fotossíntese fica limitada, ocorrendo a redução da cadeia de elétrons, sendo que a energia dos fótons passa a 
ser redirecionada para os processos que favorecem a produção de EROs (BEN AHMED et al., 2010). Os cloroplastos são uma das principais organelas geradoras de EROs intracelulares, sendo assim, as EROs podem ser geradas por transferência direta de energia de excitação da clorofila e produzir oxigênio singleto ou também pela redução do oxigênio proveniente do fotossistema I (MUNNS; TESTER, 2008). Outros tipos de estresses, como o salino e o hídrico, também foram correlacionados com a diminuição da taxa fotossintética pela diminuição da condutância estomática (CHARTZOULAKIS et al., 2002; SILVA et al., 2015).

A transpiração foliar é o principal mecanismo regulador da temperatura foliar, sendo elevada ou suprimida pela abertura e fechamento dos estômatos. Ou seja, com o fechamento dos estômatos a transpiração diminui, fazendo com que haja uma elevação na temperatura foliar (SILVA et al., 2015). Essa condição pode ser observada em condições de altas temperaturas, onde os estômatos são fechados para evitar a perda de água, e consequentemente ocorre a diminuição da taxa fotossintética por meio da limitação da condutância estomática e da transpiração (SILVA et al., 2010).

Dentre as organelas celulares os cloroplastos são responsáveis pela maior parte da produção de EROs, em que os elétrons excedentes não utilizados na assimilação de $\mathrm{CO}_{2}$ se ligam ao oxigênio formando as EROs (ASADA, 2006). Em condições ótimas, os elétrons desemparelhados se ligam ao oxigênio formando radicais superóxidos, peróxidos, e radicais hidroxilas que são naturalmente eliminados pelo metabolismo celular, mas em situações de estresse, onde há a superprodução desses radicais, ocorre o estresse oxidativo (TAIZ et al., 2017). A superprodução de EROs nos cloroplastos está ligada ao excesso de elétrons, que pode ser atribuído a baixa assimilação de $\mathrm{CO}_{2}$ causada por estresses ambientais (ASADA, 2006).

Plantas de berinjelas submetidas a estresse hídrico demonstraram que ocorre redução na concentração interna de $\mathrm{CO}_{2}$ em condições de estresse hídrico, e o mesmo padrão se repete com os parâmetros de condutância estomática, transpiração, fotossíntese liquida e eficiência instantânea de carboxilação (SILVA et al., 2015).

Um outro parâmetro fotossintético que pode ser usado para verificar limitação da fotossíntese é a relação da concentração interna de $\mathrm{CO}_{2}$ e da concentração externa de $\mathrm{CO}_{2}$ (Ci/Ca), que sendo elevada sinaliza uma condição anormal, onde não há variação na concentração externa de $\mathrm{CO}_{2}$, sendo essa elevação somente ocorrida pelo aumento da Ci. Essa elevação na $\mathrm{Ci}$ sinaliza que o $\mathrm{CO}_{2}$ que chega nas células do mesófilo não está sendo fixado na fase de carboxilação da Rubisco, possivelmente por danos causados na estrutura, o que reduz a taxa fotossintética (TATAGIBA et al., 2013). 
Quando ocorre o estresse, a P5CS1 e a P4CR se acumulam no cloroplasto, sugerindo que a biossíntese de L-prolina derivada de glutamato aumenta nos plastídios, onde ocorre a fotossíntese. A taxa do ciclo de Calvin também é reduzida, evitando a oxidação do NADPH (SZABADOS; SAVOURÉ, 2010). A produção de EROs e o acúmulo de oxigênio singleto ocorre no centro de reação do fotossistema I, e o danos causados são notados no fotossistema II, mas podem ser reduzidos pela L-prolina presente nas membranas dos tilacóides (ALIA; SARADHI; MOHANTY, 1997; CHAVES; FLEXAS; PINHEIRO, 2009). Esses danos podem ser reduzidos pela elevada taxa de biossíntese de L-prolina nos cloroplastos, que mantem baixa a relação NADPH:NADP+ e contribui para a manutenção do fluxo de elétrons, estabilizando o balanço redox e reduzindo o dano do aparato fotossintético (SZABADOS; SAVOURÉ, 2010). Nas mitocôndrias a L-prolina também exerce funções protetoras, sendo que após o estresse a oxidação da L-prolina fornece elétrons para a cadeia respiratória, contribuindo assim, para fornecer energia para a continuidade do desenvolvimento das plantas (HARE; CRESS, 1997).

Em plantas de grão de bico sobre estresse por Cádmio em pequena concentração (25 $\mathrm{mg} / \mathrm{kg}$ ), a aplicação exógena da L-prolina aumentou os parâmetros de condutância estomática, concentração interna de $\mathrm{CO}_{2}$, eficiência no uso da água e transpiração quando comparado ao controle. Em condições de $50 \mathrm{mg} / \mathrm{kg}$ de solo, os parâmetros fotossintéticos se igualaram ao controle e em plantas não estressadas, a aplicação de L-prolina promoveu aumentos significativos na condutância estomática, concentração interna de $\mathrm{CO}_{2}$, eficiência no uso da água e transpiração, evidenciando assim o efeito positivo da L-prolina na manutenção do aparato fotossintético (HAYAT et al., 2013).

Plantas de oliveira submetidas a estresse salino, apresentaram maior condutância estomática e transpiração em plantas onde ocorreram aplicação exógena de L-prolina do que quando comparada aos tratamentos sem uso da L-prolina exógena (BEN AHMED et al., 2010). O uso de L-prolina exógena em mudas de tamareira submetidas a estresse por Cádmio, elevou a taxa fotossintética a eficiência no uso da água e a condutividade estomática das plantas quando comparadas com o tratamento sem aplicação de L-prolina (ZOUARI et al., 2016). Em estudos com oliveiras sob condição de déficit hídrico, Ahmed et al. (2009), verificou redução na fotossíntese, condutância estomática e transpiração como efeito do estresse hídrico, nos quais também foi relatado aumento na concentração de L-prolina. Nesse mesmo estudo, que foi realizado com três cultivares de oliveiras, Ahmed et al. (2009), verificou que o cultivar com maior acúmulo de L-prolina nas folhas foi mais responsivo nos parâmetros avaliados, correlacionandose assim, a atuação da L-prolina no auxílio da manutenção das atividades fotossintéticas das plantas mesmo em condições de estresse. 


\section{MATERIAL E MÉTODOS}

\subsection{Características Gerais da Área experimental}

O experimento foi conduzido de 04 de julho a 8 de novembro de 2017, em casa de vegetação com telhado tipo arco de 6,4 $\mathrm{m}$ de largura por $42 \mathrm{~m}$ de comprimento, com pé direito de 3,4 m, coberta com filme de polietileno aditivado anti-UV com $150 \mu \mathrm{m}$ de espessura, e laterais cobertas com tela antiafideo, localizada em Piracicaba - SP, na área experimental do Departamento de

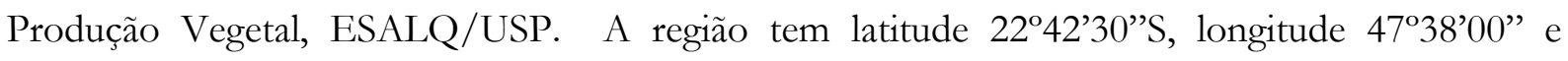
altitude $546 \mathrm{~m}$ Segundo a classificação climática de Köppen, o clima é do tipo Cwa, subtropical de inverno seco (com temperaturas inferiores a $18^{\circ} \mathrm{C}$ ) e verão quente (com temperaturas superiores a $\left.22^{\circ} \mathrm{C}\right)$.

\subsection{Tratamentos e delineamento experimental}

O experimento foi conduzido em delineamento inteiramente casualizado com quatro repetições e sete tratamentos, compostos pelas seguintes doses de L-prolina, em mg/L: 0, 50, 100, 200, 400, 800 e 1600 .Esse aminoácido foi aplicado através de pulverizações dirigidas para a planta com objetivo de realizar a cobertura completa dos tecidos vegetais, com um volume de solução adequado para cada estádio de desenvolvimento da planta a fim de não provocar escorrimento superficial. As parcelas foram compostas por oito plantas, sendo as quatro centrais utilizadas como parcela útil.

As aplicações foliares de L-prolina foram feitas aos 30, 51, 66, 80, 93 e 108 dias após o transplante das mudas (DAT), por meio de um pulverizador costal pressurizado com $\mathrm{CO}_{2}$ e com pressão constante, cujos volumes da solução empregados em cada tratamento foram em litros, de 0,$8 ; 1,0 ; 1,2 ; 1,21,4$ e 1,4 respectivamente para os períodos indicados anteriormente (Figura 1). 


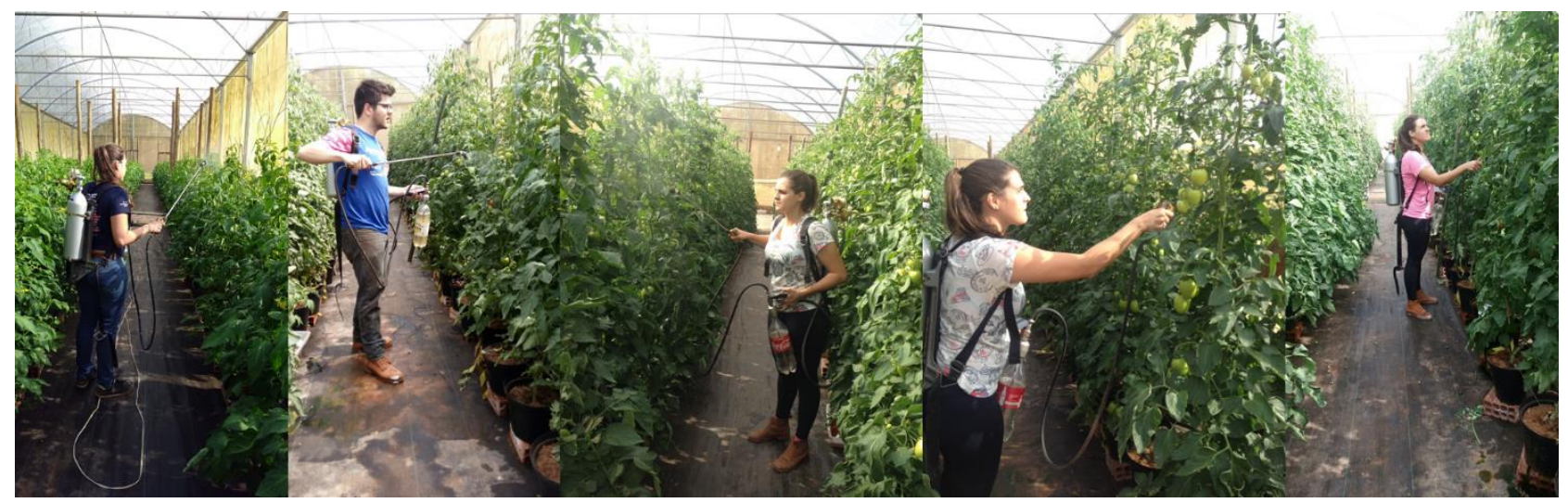

Figura 1. Aplicações realizadas nos tomateiros.

\subsection{Produção e Transplante das Mudas}

O cultivar de tomate utilizado foi o híbrido Pizzadoro, do tipo italiano e com hábito de crescimento indeterminado, que apresenta elevada resistência a murcha de verticílio ( $\mathrm{Va}$ e $\mathrm{Vd}$ ), murcha de fusário (Fol:0,1), pinta bacteriana (Pst), vírus do mosaico do tomate (ToMV) e resistência intermediária aos nematóides (Meloidogyne arenaria, Meloidogyne incognita, Meloidogyne javanica).

As mudas foram obtidas do viveiro de mudas denominado Celeiro Verde, localizado em Mogi Guaçu - SP. As mudas foram produzidas em bandejas plásticas de 128 células preenchidas com substrato à base de fibra de coco. As mudas foram transplantadas quando apresentaram quatro folhas definitivas, ou seja, aos 34 dias após a semeadura, para vasos plásticos de oito litros preenchidos com substrato de fibra de coco (Figura 2). Os vasos foram colocados em casa de vegetação, no espaçamento de 0,4 m entre plantas, 0,8 m entre linhas e 1,4 m entre linhas duplas (Figura 3).

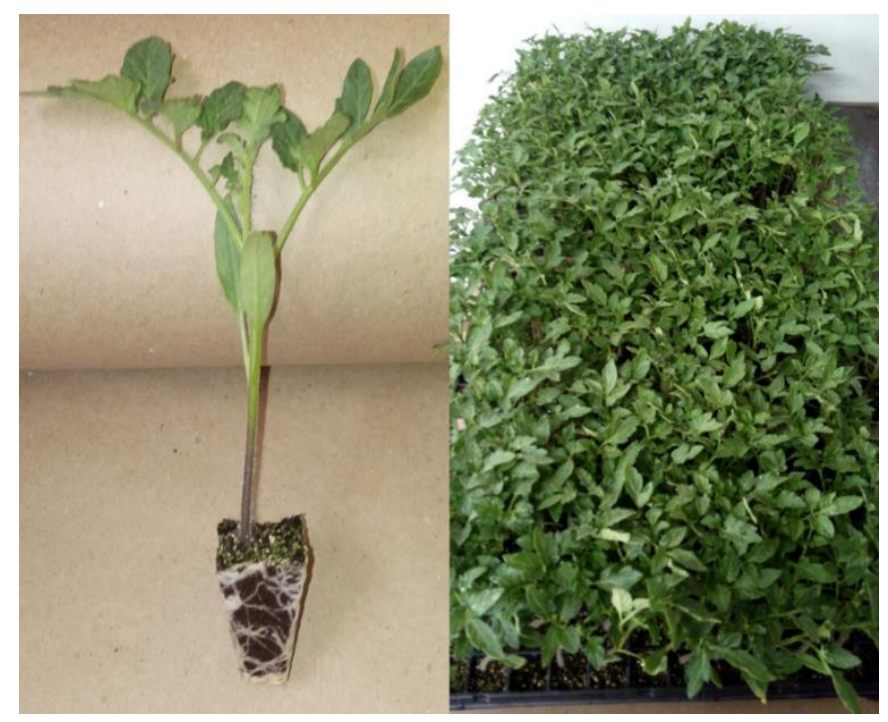

Figura 2. Mudas do tomateiro aos 34 dias após a semeadura. 


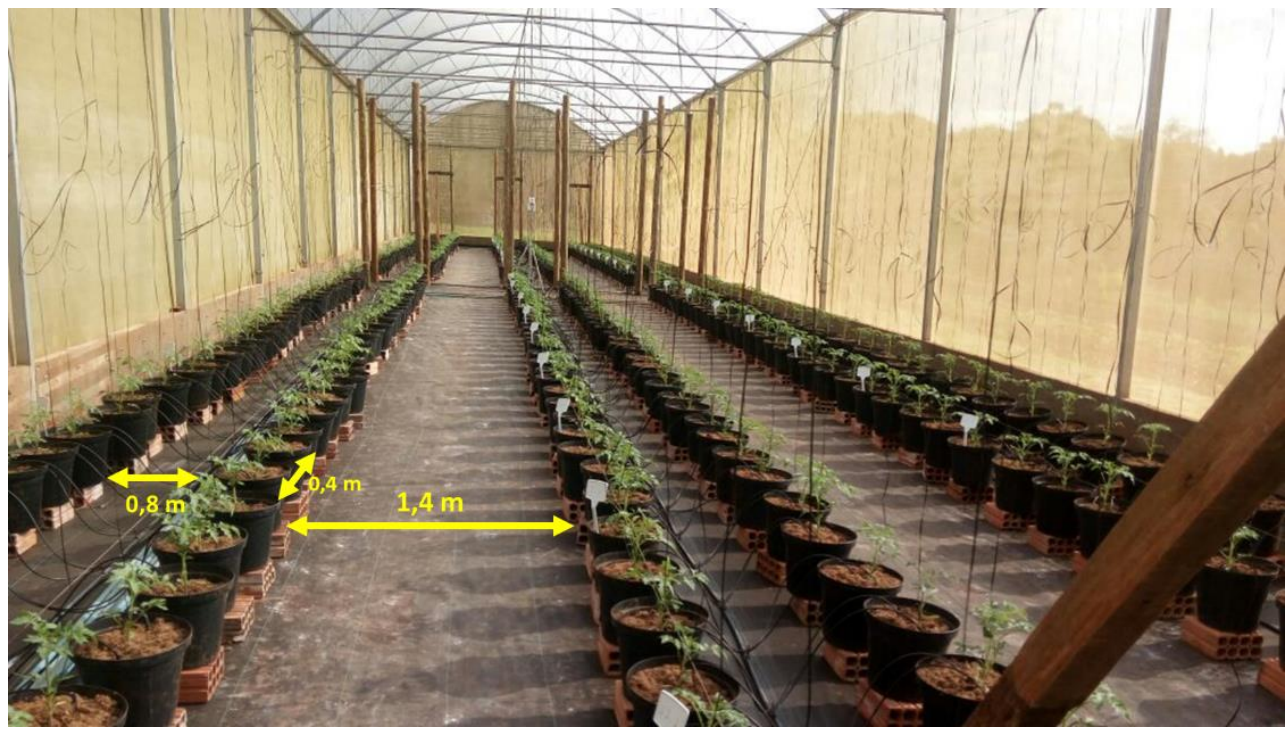

Figura 3. Vista geral da estufa e alocação dos vasos

\subsection{Manejo da cultura}

\subsubsection{Sistema de condução das plantas}

As plantas foram conduzidas com uma haste no sentido vertical até $2,5 \mathrm{~m}$ de altura quando foi realizado o corte da gema apical. As brotações originárias das axilas das folhas foram retiradas semanalmente, e após cada operação as plantas foram pulverizadas com fungicidas cúpricos.

No período reprodutivo, as pencas foram mantidas com cinco frutos, e para isso realizou-se o desbaste dos frutos excedentes (Figura 4).

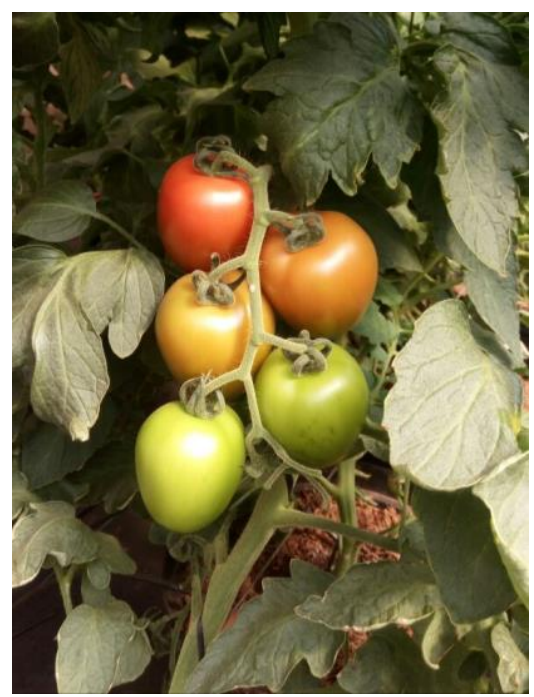

Figura 4. Pencas contendo 5 frutos após desbaste. 


\subsubsection{Manejo da irrigação e nutrição das plantas}

O Sistema de irrigação foi composto por uma bomba de 0,5 cv, um reservatório de 1000 litros, mangueiras de polietileno e por gotejadores autocompensantes com vazão de $4 \mathrm{~L} /$ hora. O sistema foi automatizado e, monitorado pelo sistema gasoso de controle de irrigação (Tensiômetro Irrigás), que acionava a irrigação/fertirrigação quando a tensão de água no substrato atingia $3 \mathrm{kPa}$. Para cada vaso foram utilizados dois gotejadores (Figura 5).

As soluções nutritivas foram formuladas para suprir as exigências em nutrientes das plantas em cada estádio de crescimento, sendo a primeira utilizada do transplante até os 30 DAT, a segunda dos 31 até os 60 DAT, a terceira dos 61 aos 90 DAT e a quarta dos 91 aos 127 DAT. A composição de cada solução em mg/L foi : a) primeira solução: 125 N, 80 P, 225 K, 120 Ca, 40 $\mathrm{Mg}, 61 \mathrm{~S}, 1,31$ B, 2,02 Fe, 0,46 Cu, 0,46 Mn, 0,09 Mo, 0,09 Ni e 0,18 Zn; b) segunda solução: 120 N, 50 P, 266 K, 120 Ca, 40 Mg, 133 S, 1,31 B, 2,02 Fe, 0,46 Cu, 0,46 Mn, 0,09 Mo, 0,09 Ni e 0,18 Zn; c) terceira solução: 130 N, 80 P, 390 K, 160 Ca, 50 Mg, 20 S, 1,31 B, 2,02 Fe, 0,46 Cu, 0,46 Mn, 0,09 Mo, 0,09 Ni e 0,18 Zn; e d) quarta solução: 130 N, 80 P, 360 K, 160 Ca 50 Mg, 146 S, 1,31 B, 2,02 Fe, 0,46 Cu, 0,46 Mn, 0,09 Mo, 0,09 Ni e 0,18 Zn.

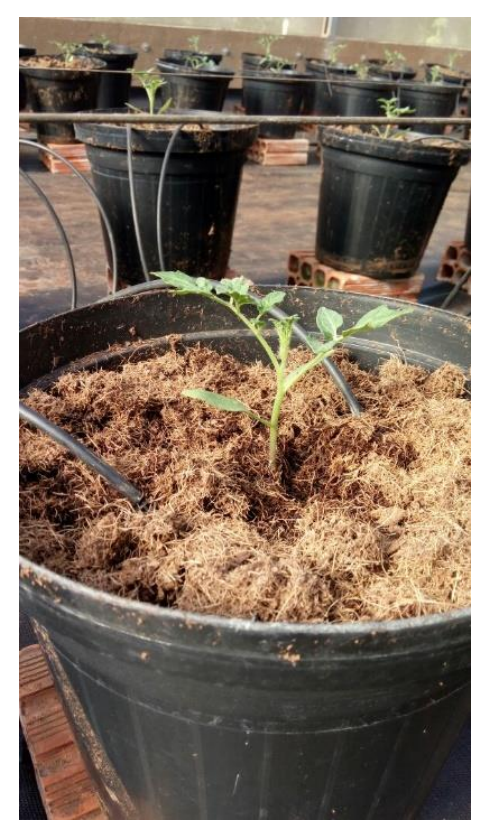

Figura 5. Detalhe da localização dos gotejadores nos vasos.

\subsubsection{Dados meteorológicos}

Os dados de temperatura, umidade relativa do ar e radiação fotossinteticamente ativa no interior da estufa foram registrados a cada 30 minutos por uma miniestação meteorológica (Watchdog 2475 Plant Grow Station) posicionada no centro da estufa a uma altura de 1,5 m. Os 
dados foram expressos pelas médias diárias das temperaturas máximas, mínimas e médias e umidade relativa do ar. Os valores de radiação fotossinteticamente ativa foram expressos pela intensidade luminosa alcançada diariamente, expressa $\mathrm{em} \mathrm{mol} / \mathrm{m}^{2} / \mathrm{dia}$.

\subsection{Teores foliares de nutrientes}

Para análise nutricional das folhas, foi coletada a quarta folha totalmente expandida (folha diagnóstica) a partir do ponteiro, no período do florescimento (50 DAT), seguindo a metodologia descrita por Malavolta et al. (1997). Sendo assim, foram coletadas 4 folhas por parcela e posteriormente secadas em estufa a $65^{\circ} \mathrm{C}$ com circulação forçada de ar, por 48 horas, cujas amostras foram enviadas para o laboratório Pirasolo, localizado em Piracicaba-SP.

\subsection{Parâmetros fotossintéticos}

Os parâmetros fotossintéticos foram medidos com o uso de um medidor portátil "infrared gas analyzer" (IRGA, LI 6400XT, LI-COR; Lincoln, Nebraska, USA), aos 69 DAT (florescimento pleno). Para as medições foram utilizadas a $4^{a}$ folha totalmente expandida a partir do ápice (em plena atividade fotossintética), no total de uma folha por parcela (Figura 6). Os parâmetros mensurados foram concentração interna de carbono ( $\mathrm{Ci}-\mu \mathrm{mol} \mathrm{CO}_{2} \mathrm{~mol}^{-1}$ ), condutância estomática ( $\mathrm{Gs}-\mathrm{mol}$ de $\mathrm{H}_{2} \mathrm{O} \mathrm{m}^{-2} \mathrm{~s}^{-1}$ ), transpiração $\left(\mathrm{E}-\mathrm{mmol}\right.$ de $\left.\mathrm{H}_{2} \mathrm{O} \mathrm{m}^{-2} \mathrm{~s}^{-1}\right)$, taxa de fotossíntese líquida (A - $\mu \mathrm{mol}$ de $\mathrm{CO}_{2} \mathrm{~m}^{-2} \mathrm{~s}^{-1}$ ), eficiência do fotossistema II (PhiPSII), transporte aparente de elétrons (ETR- $\mu \mathrm{mol}$ (elétrons) $\mathrm{m}^{-2} \mathrm{~s}^{-1}$ ), eficiência instantânea do uso da água (WUE - A/E), calculada pela relacão entre a fotossíntese líquida e a transpiração $\left(\mu \mathrm{mol} \mathrm{m} \mathrm{m}^{-2} \mathrm{~s}^{-1}\right) /\left(\mathrm{mmol} \mathrm{de} \mathrm{H}_{2} \mathrm{O}\right.$ $\left.\mathrm{m}^{-2} \mathrm{~s}^{-1}\right)$, e a eficiência instantânea de carboxilação $\left(\mathrm{EiC}-\mathrm{A} / \mathrm{Ci}-\left(\mu \mathrm{mol} \mathrm{m} \mathrm{s}^{-1}\right) /\left(\mu \mathrm{mol} \mathrm{CO} \mathrm{C}^{-2}\right)\right)$ calculada a partir da relação entre a fotossíntese líquida e a concentração interna de carbono. 


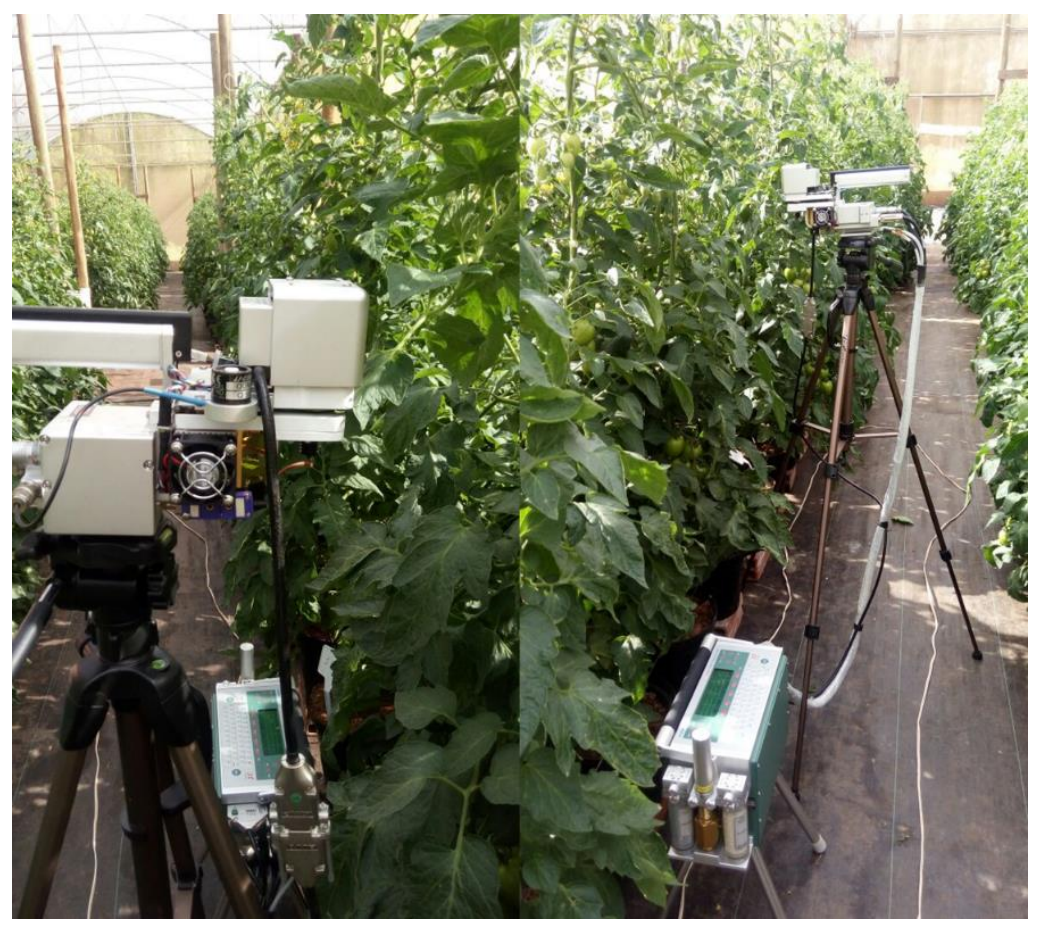

Figura 6. Medição dos parâmetros fotossintéticos com o IRGA.

\subsection{Análises bioquímicas}

As coletas de folhas para análises bioquímicas foram realizadas aos 69 e 96 DAT. Os materiais coletados foram imediatamente congelados em nitrogênio líquido, e posteriormente macerados em moinho específico para esse tipo de material vegetal. Após essa etapa, os materiais macerados foram armazenados em freezer a $-80^{\circ} \mathrm{C}$ em tubos Falcon de $50 \mathrm{ml}$ (Figura 7).

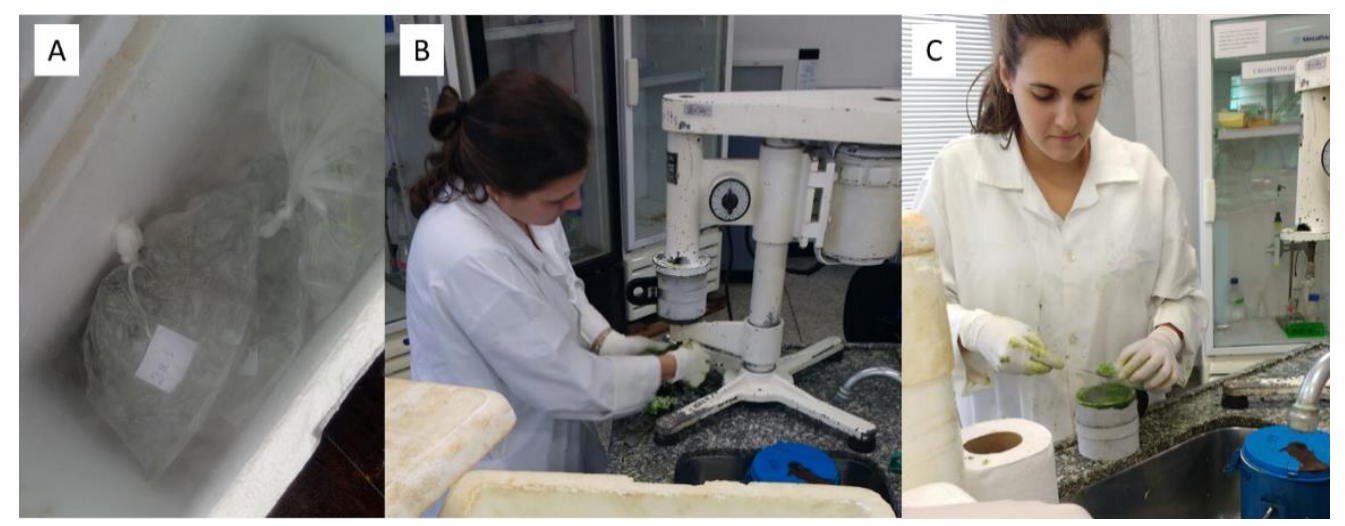

Figura 7. Primeiras etapas das análises bioquímicas. (A) coleta da folhas e congelamento imediato em nitrogênio líquido. (B) maceração em moinho e (C) armazenamento em tubos Falcon. 


\subsubsection{Extração de proteínas solúveis}

Para determinação das enzimas antioxidantes SOD, GR, CAT e APX, foi necessário primeiro realizar a extração e quantificação das proteínas solúveis presentes na amostra vegetal. Dessa maneira, a extração foi realizada seguindo a metodologia de Azevedo et al. (1998), adicionando $1 \mathrm{~g}$ do tecido vegetal macerado em 4\% de PVPP (Polivinilpolipirrolidona) e $3 \mathrm{ml} \mathrm{de}$ tampão fosfato $100 \mathrm{mM}$ (pH 7,5), contendo $1 \mathrm{mM}$ de EDTA e $3 \mathrm{mM}$ de DTT. Após essa etapa as amostras foram centrifugadas a $10000 \mathrm{rpm}$, por 30 minutos a $4^{\circ} \mathrm{C}$ e o sobrenadante pipetado e dividido em alíquotas para posterior medição de quantidade de proteínas solúveis e atividades das enzimas antioxidantes.

\subsubsection{Quantificação de proteínas solúveis}

O teor de proteínas foi utilizado nos cálculos das atividades enzimáticas e para tal, foi determinado pela metodologia de Bradford (1976), onde foi tomada uma alíquota de $20 \mu \mathrm{L}$ do extraído de proteínas, que recebeu $2 \mathrm{ml}$ do reagente de Bradford. Essa mistura foi agitada e mantida em repouso por 2 minutos. Após isso foi realizada a leitura em espectrofotômetro a 595 $\mathrm{nm}$, sendo os resultados obtidos em $\mathrm{mg} / \mathrm{ml}$.

\subsubsection{Catalase - CAT (EC 1.11.1.6)}

A determinação de catalase (CAT) seguiu a metodologia proposta por Kraus; Mckersie; Fletcher (1995) com algumas adaptações conforme Azevedo et al. (1998). A determinação ocorreu com a adição de $25 \mu \mathrm{L}$ de extrato vegetal em $1 \mathrm{ml}$ de uma solução de tampão fosfato 100 $\mathrm{mM}(\mathrm{pH} 7,5)$ contendo $2,5 \mu \mathrm{L}$ de peróxido de hidrogênio $\left(\mathrm{H}_{2} \mathrm{O}_{2}, 30 \%\right)$, sendo a leitura realizada em espectrofotômetro por 1 minuto a $240 \mathrm{~nm}$.

\subsubsection{Ascorbato peroxidase - APX (EC 1.11.1.11)}

A atividade da enzima ascorbato peroxidase (APX) foi determinada seguindo a metodologia de Moldes (2008) e Nakano e Assada (1981), onde $50 \mu \mathrm{L}$ do extrato vegetal foram adicionados em cubetas contendo $650 \mu \mathrm{L}$ do tampão fosfato de potássio $80 \mathrm{mM}(\mathrm{pH} 7,0), 100 \mu \mathrm{L}$ de ascorbato, $100 \mu \mathrm{L}$ de EDTA e $100 \mu \mathrm{L}$ de peróxido de hidrogênio. As leituras foram feitas em espectrofotômetro a $290 \mathrm{~nm}$. 


\subsubsection{Superóxido dismutase - SOD (EC 1.15.1.1)}

A atividade da enzima superóxido dismutase (SOD) foi determinada seguindo a metodologia proposta por Giannopolitis \& Ries (1977), com modificações propostas por Cembrawska-Lech et al. (2015), por espectrofotometria. A reação foi conduzida em câmara de reação sob iluminação de lâmpada fluorescente a $25^{\circ} \mathrm{C}$. A determinação foi feita pela adição de tampão de fosfato de potássio 0,1 M (pH 7,8), 1,3 $\mu \mathrm{M}$ de riboflavina, $13 \mathrm{mM}$ de metionina, $63 \mu \mathrm{M}$ de NBT e 0,1 $\mathrm{mM}$ de EDTA, em $100 \mu \mathrm{L}$ do extrato proteico, ficando 5 minutos sob iluminação e a leitura realizada a $560 \mathrm{~nm}$.

\subsubsection{Glutationa redutase - GR (EC 1.6.4.2)}

A atividade da enzima glutationa redutase (GR) foi determinada de acordo com a metodologia proposta por Gomes-Junior et al. (2006) e com algumas modificações segundo Azevedo et al. (1998). Em uma solução composta por $3 \mathrm{ml}$ de tampão de fosfato de potássio (100 mM, pH 7,5), $1 \mathrm{ml}$ de DTNB (2-nitrobenzoic acid, NBT), 1 mM de GSSG (glutationa oxidada) e 0,1 $\mathrm{mM}$ de NADPH, foi adicionado $50 \mu \mathrm{L}$ de extrato proteico. A leitura foi realizada a $412 \mathrm{~nm}$ por 1 minuto, em espectrofotômetro.

\subsubsection{Peroxidação lipídica}

A avaliação da peroxidação lipídica foi realizada segundo a metodologia de Heath e Packer (1968), onde 0,2 g do material vegetal fresco foi macerado em $2 \mathrm{ml}$ de ácido tricloroacético (TCA, 0,1\%), contendo aproximadamente $20 \%$ de PVPP. Após a homogeneização, a mistura foi centrifugada a $10000 \mathrm{rpm}$ por $10 \mathrm{~min}$ a $4^{\circ} \mathrm{C}$. Após a centrifugação, $250 \mu \mathrm{L}$ do sobrenadante foi pipetado e a ele adicionado $1 \mathrm{ml}$ de uma solução contendo $20 \%$ de TCA e $0,5 \%$ de ácido tiobarbitúrico. A mistura foi mantida por 30 minutos a $95^{\circ} \mathrm{C}$. Após os 30 minutos, a reação foi resfriada em gelo e mantida a temperatura ambiente para a realização da leitura em espectrofotômetro a 532 e $600 \mathrm{~nm}$. O resultado final foi expresso em concentração de malonaldeído (MDA).

\subsubsection{Conteúdo de peróxido de hidrogênio}

A determinação do conteúdo de peróxido de hidrogênio foi conduzida de acordo com a metodologia de Alexieva et al. (2001), sendo que $0,2 \mathrm{~g}$ do material vegetal fresco foi macerado em 
$2 \mathrm{ml}$ de ácido tricloroacético (TCA, 0,1\%), contendo aproximadamente 20\% de PVPP. Após a homogeneização a mistura foi centrifugada a $10000 \mathrm{rpm}$ por $10 \mathrm{~min}$ a $4^{\circ} \mathrm{C}$. Após a centrifugação, $0,2 \mathrm{ml}$ do sobrenadante foi pipetado e adicionado em $0,2 \mathrm{ml}$ do tampão fosfato de potássio (100 $\mathrm{mM}, \mathrm{pH} 7,5)$ e $0,8 \mathrm{ml}$ de iodeto de potássio $1 \mathrm{M}$, sendo incubado por 1 hora na ausência da luz. A leitura foi realizada em espectrofotômetro a $390 \mathrm{~nm}$.

\subsection{Produtividade}

A produtividade final foi calculada pela somatória das colheitas realizadas semanalmente. Dessa maneira, os frutos foram classificados de acordo com a normas sugeridas pelo "Programa Brasileiro para Modernização da Horticultura - Normas de Classificação do Tomate", (2003) com algumas adaptações, sendo classificados (peso e número) em pequenos (diâmetro equatorial de 40 a $50 \mathrm{~mm}$ ), médios (diâmetro equatorial de 50 a $60 \mathrm{~mm}$ ), grandes (diâmetro equatorial $>60 \mathrm{~mm}$ ) e não comerciais (diâmetro equatorial $<40 \mathrm{~mm}$ ), conforme exemplificado na Figura 8.

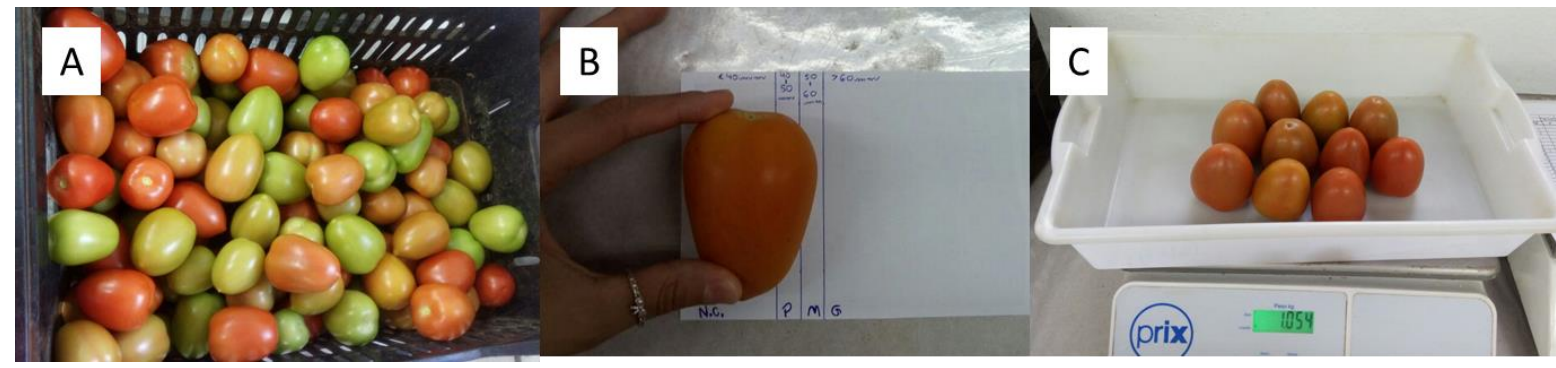

Figura 8. Colheita e classificação dos tomates. (A) ponto de maturação selecionado para a colheita dos frutos, (B) classificação por tamanho e (C) pesagem dos frutos colhidos.

\subsection{Características qualitativas}

As características qualitativas dos frutos foram avaliadas aos 100 DAT com a coleta de 4 frutos representativos por parcela, triturados e homogeneizados (Figura 9). O teor de sólido solúveis totais (SST, em ${ }^{\circ}$ Brix) foi determinado por leitura direta da polpa homogeneizada com uso de um refratômetro (marca Atago, modelo PR-32 $\alpha$ ). A acidez total titulável (ATT) foi determinada segundo a metodologia proposta por Carvalho et al. (1990), onde 10g de polpa homogeneizada foram diluídas em $90 \mathrm{ml}$ de água destilada. A titulação foi feita com solução de hidróxido de sódio $0,05 \mathrm{~N}$ até que o $\mathrm{pH}$ atingisse 8,1, por meio do uso de um pHmetro digital. A relação SST/ATT também foi calculada, pois é uma importante ferramenta na caracterização do 
sabor (CHITARRA, M. I. F.; CHITARRA, 2005). Para determinação de ácido ascórbico, 10 g da polpa homogeneizada foram diluídas em $90 \mathrm{ml}$ de ácido oxálico (1\%). Posteriormente, realizou-se a titulação com uma solução de 2,6-diclorofenol-indofenol até ocorrer a virada de coloração, segundo a metodologia de Carvalho et al. (1990).

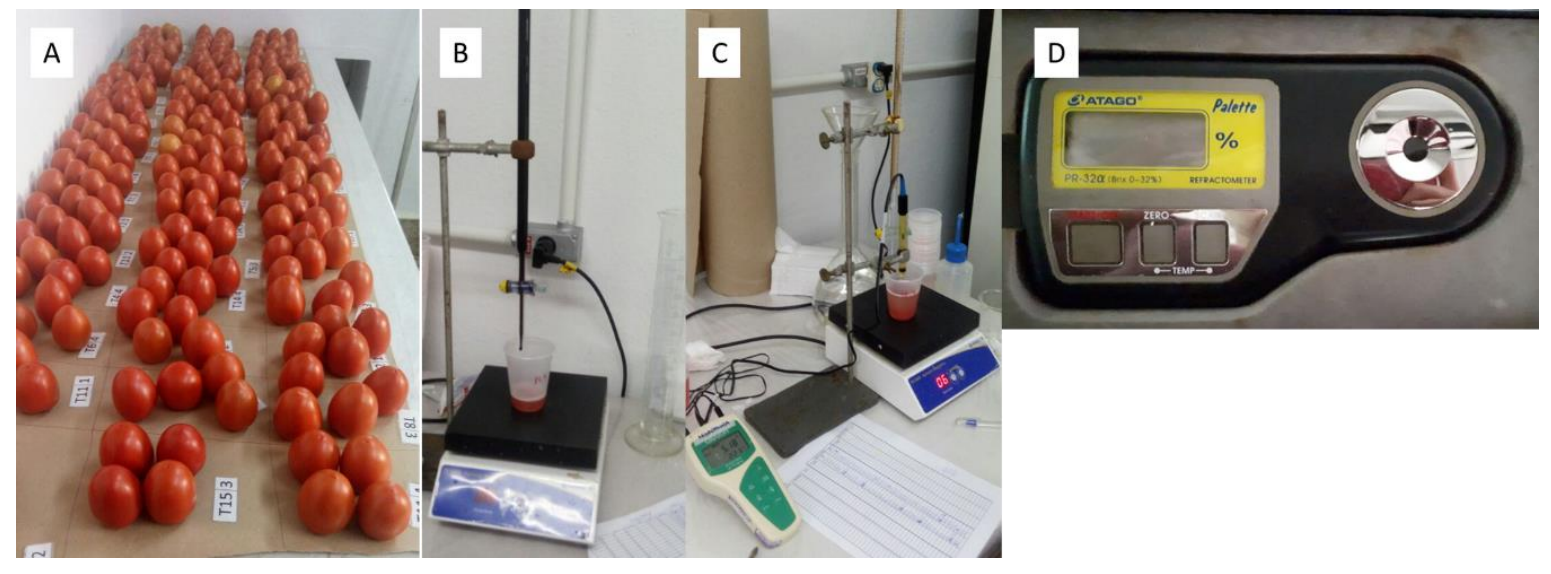

Figura 9. (A) frutos separados para as análises quantitativas, (B) determinação de ácido ascórbico, (C) determinação de acidez titulável e (D) equipamento utilizado na determinação dos sólidos solúveis totais. 


\section{RESULTADOS}

\subsection{Microclima no interior da casa de vegetação}

Durante o ciclo do tomateiro, ocorreram temperaturas fora da faixa ideal citado por Alvarenga (2013). Segundo esse autor, as temperaturas ideais para as fases de florescimento, pegamento e maturação dos frutos são: 18 a $24^{\circ} \mathrm{C} ; 14$ a $17^{\circ} \mathrm{C}$ (noturna) e 19 a $24^{\circ} \mathrm{C}$ (diurna); e 20 a $24^{\circ} \mathrm{C}$, respectivamente. Uma termoperiodicidade entre o dia e a noite deve ocorrer entre 7 e $8^{\circ} \mathrm{C}$ para o ótimo desenvolvimento do tomateiro. Nesse estudo, temperaturas noturnas entre 25 a $30,5^{\circ} \mathrm{C}$, consideradas extremas, ocorreram em 51 dias. Temperaturas diurnas entre 25 e $35^{\circ} \mathrm{C}$ ocorreram durante quase todo o clico de cultivo (115 dias) e temperaturas extremas $\left(35\right.$ a $38,9^{\circ} \mathrm{C}$ ) foram registradas em 23 dias. Desde o início do florescimento até o final desse processo, que compreendeu o período de 27 a $102 \mathrm{DAT}$, foram observadas temperaturas entre 25 e $35^{\circ} \mathrm{C}$ em 62 dias, e acima de $35^{\circ} \mathrm{C}$ em 15 dias (Figura 10).

A radiação fotossinteticamente ativa durante todo o ciclo de cultivo, teve valor médio de 13,57 $\mathrm{mol} \mathrm{m}^{-2} \mathrm{dia}^{-1}$, atingindo valor mínimo de 4,21 $\mathrm{mol} \mathrm{m}^{-2} \mathrm{dia}^{-1}$ aos 14 DAT e valor máximo de 21,02 $\mathrm{mol} \mathrm{m}^{-2} \mathrm{dia}^{-1}$ aos 63 DAT.

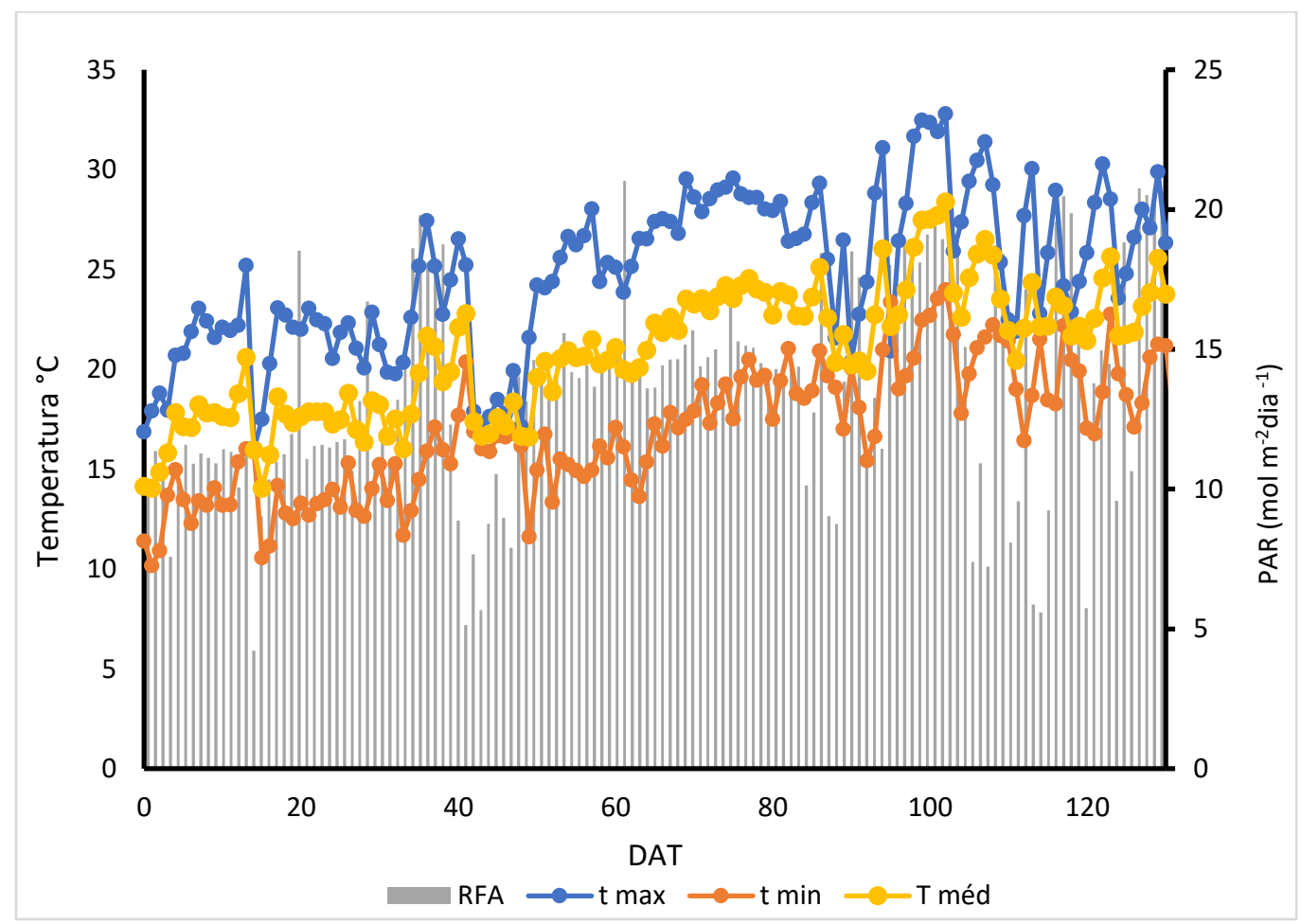

Figura 10. Radiação fotossinteticamente ativa (RFA), temperatura média (T méd), temperatura máxima ( T máx) e temperatura mínima ( $\mathrm{T}$ min) registradas durante a condução do experimento. 


\subsection{Teores foliares de nutrientes}

A aplicação de L-prolina não incrementou os teores de macronutrientes quando comparados com o tratamento controle (Tabela 1$)$.

Os teores de cálcio $(8,15$ a 9,93 g/ $\mathrm{kg}$ ) e magnésio $(2,93$ a 3,39 $\mathrm{g} / \mathrm{kg})$ nas folhas amostradas aos 50 DAT foram menores que os considerados adequados para a cultura do tomateiro (MALAVOLTA; VITTI; OLIVEIRA, 1997), cujos valores variaram de 14 a $40 \mathrm{~g} / \mathrm{kg}$ e 4 a 8 g/kg, respectivamente. Porém, sintomas visuais de deficiência não foram observados durante o desenvolvimento das plantas.

Tabela 1. Teores de Nitrogênio (N), Fósforo (P), Potássio (K), Cálcio (Ca), Magnésio (Mg) e Enxofre (S) em folhas de plantas de tomate aos 50 DAT sob aplicação de L-prolina.

\begin{tabular}{ccccccc}
\hline $\begin{array}{c}\text { Doses de L- } \\
\text { prolina }(\mathrm{mg} / \mathrm{L})\end{array}$ & $\mathrm{N}(\mathrm{g} / \mathrm{kg})$ & $\mathrm{P}(\mathrm{g} / \mathrm{kg})$ & $\mathrm{K}(\mathrm{g} / \mathrm{kg})$ & $\mathrm{Ca}(\mathrm{g} / \mathrm{kg})$ & $\mathrm{Mg}(\mathrm{g} / \mathrm{kg})$ & $\mathrm{S}(\mathrm{g} / \mathrm{kg})$ \\
\hline 0 & $39,72 \pm 4,86 \mathrm{a}$ & $7,15 \pm 0,47 \mathrm{a}$ & $44,25 \pm 3,70 \mathrm{a}$ & $9,93 \pm 1,17 \mathrm{a}$ & $3,39 \pm 0,14 \mathrm{a}$ & $8,13 \pm 1,44 \mathrm{a}$ \\
50 & $39,37 \pm 1,05 \mathrm{a}$ & $7,40 \pm 0,56 \mathrm{a}$ & $42,05 \pm 6,67 \mathrm{a}$ & $8,73 \pm 1,23 \mathrm{a}$ & $3,00 \pm 0,13 \mathrm{a}$ & $7,53 \pm 1,65 \mathrm{a}$ \\
100 & $39,90 \pm 1,90 \mathrm{a}$ & $7,33 \pm 0,54 \mathrm{a}$ & $39,83 \pm 1,70 \mathrm{a}$ & $8,15 \pm 0,76 \mathrm{a}$ & $3,13 \pm 0,09 \mathrm{a}$ & $5,48 \pm 0,46 \mathrm{a}$ \\
200 & $40,42 \pm 1,55 \mathrm{a}$ & $7,65 \pm 0,17 \mathrm{a}$ & $40,08 \pm 4,06 \mathrm{a}$ & $8,55 \pm 0,57 \mathrm{a}$ & $3,07 \pm 0,15 \mathrm{a}$ & $6,23 \pm 0,46 \mathrm{a}$ \\
400 & $40,60 \pm 2,62 \mathrm{a}$ & $7,33 \pm 0,48 \mathrm{a}$ & $40,25 \pm 3,00 \mathrm{a}$ & $7,98 \pm 0,75 \mathrm{a}$ & $3,02 \pm 0,12 \mathrm{a}$ & $6,35 \pm 0,91 \mathrm{a}$ \\
800 & $40,25 \pm 2,46 \mathrm{a}$ & $7,60 \pm 0,18 \mathrm{a}$ & $37,65 \pm 4,38 \mathrm{a}$ & $8,50 \pm 1,39 \mathrm{a}$ & $3,08 \pm 0,45 \mathrm{a}$ & $6,35 \pm 0,40 \mathrm{a}$ \\
1600 & $39,90 \pm 2,21 \mathrm{a}$ & $7,05 \pm 0,40 \mathrm{a}$ & $39,15 \pm 2,80 \mathrm{a}$ & $8,48 \pm 0,40 \mathrm{a}$ & $2,93 \pm 0,18 \mathrm{a}$ & $6,10 \pm 1,56 \mathrm{a}$ \\
\hline
\end{tabular}

\subsection{Parâmetros fotossintéticos}

A fotossíntese líquida, a condutância estomática, a eficiência do fotossistema II (Tabela 2) e o transporte aparente de elétrons (Tabela 3), não foram afetados significativamente pela aplicação exógena da L-prolina, embora a aplicação de $100 \mathrm{mg} / \mathrm{L}$ elevou os valores absolutos desses parâmetros. A aplicação de $100 \mathrm{mg} / \mathrm{L}$ de L-prolina proporcionou maior eficiência instantânea no uso da água (WUE) em relação ao controle e às doses de 200, 400, 800 e $1600 \mathrm{mg} / \mathrm{L}$ de L-prolina (Tabela 3). A dose de $100 \mathrm{mg} / \mathrm{L}$ de L-prolina aumentou também a eficiência instantânea de carboxilação (EiC) em relação ao controle e aos demais tratamentos (Tabela 3). 
Tabela 2. Taxa fotossintética líquida (A), condutância estomática (Gs), concentração intercelular disponível de $\mathrm{CO}_{2}$ (Ci) e eficiência do fotossistema II (PhiPS2) em folhas de plantas de tomate sob aplicação de L-prolina. Medidas obtidas das 14 às 16 horas, aos 69 DAT.

\begin{tabular}{ccccc}
\hline $\begin{array}{c}\text { Doses de L- } \\
\text { prolina }(\mathrm{mg} / \mathrm{L})\end{array}$ & $\mathrm{A}(\mu \mathrm{mol} \mathrm{CO} 2 \mathrm{~m}-2 \mathrm{~s}-1)$ & $\mathrm{Gs}(\mathrm{mol} \mathrm{H} 2 \mathrm{O} \mathrm{m}-2 \mathrm{~s}-1)$ & $\mathrm{Ci}(\mu \mathrm{mol} \mathrm{CO} 2 \mathrm{~mol}-1)$ & PhiPS2 \\
\hline 0 & $15,16 \pm 3,65 \mathrm{a}$ & $0,35 \pm 0,06 \mathrm{a}$ & $299,77 \pm 29,95 \mathrm{a}$ & $0,34 \pm 0,04 \mathrm{a}$ \\
50 & $17,05 \pm 2,30 \mathrm{a}$ & $0,33 \pm 0,08 \mathrm{a}$ & $285,80 \pm 16,50 \mathrm{a}$ & $0,35 \pm 0,06 \mathrm{a}$ \\
100 & $23,26 \pm 10,90 \mathrm{a}$ & $0,37 \pm 0,15 \mathrm{a}$ & $266,95 \pm 44,94 \mathrm{a}$ & $0,41 \pm 0,07 \mathrm{a}$ \\
200 & $12,91 \pm 1,84 \mathrm{a}$ & $0,29 \pm 0,05 \mathrm{a}$ & $298,07 \pm 17,58 \mathrm{a}$ & $0,28 \pm 0,05 \mathrm{a}$ \\
400 & $14,81 \pm 6,25 \mathrm{a}$ & $0,32 \pm 0,12 \mathrm{a}$ & $293,48 \pm 38,35 \mathrm{a}$ & $0,34 \pm 0,06 \mathrm{a}$ \\
800 & $14,14 \pm 6,19 \mathrm{a}$ & $0,34 \pm 0,17 \mathrm{a}$ & $298,96 \pm 25,55 \mathrm{a}$ & $0,33 \pm 0,08 \mathrm{a}$ \\
1600 & $16,42 \pm 3,70 \mathrm{a}$ & $0,35 \pm 0,04 \mathrm{a}$ & $293,69 \pm 27,11 \mathrm{a}$ & $0,34 \pm 0,04 \mathrm{a}$ \\
\hline
\end{tabular}

Tabela 3. Transporte aparente de elétrons (ETR), transpiração (E), eficiência no uso da água (WUE) e eficiência instantânea da carboxiliação (EiC) em folhas de plantas de tomate sob aplicação de L-prolina. Medidas obtidas das 14 às 16 horas, aos 69 DAT.

\begin{tabular}{ccccc}
\hline $\begin{array}{c}\text { Doses de L-prolina } \\
(\mathrm{mg} / \mathrm{L})\end{array}$ & $\begin{array}{c}\text { ETR ( }(\mu \mathrm{mol} \text { (elétrons) } \\
\mathrm{m}-2 \mathrm{~s}-1)\end{array}$ & $\mathrm{E}(\mathrm{mmol} \mathrm{H} 2 \mathrm{O} \mathrm{m}-2 \mathrm{~s}-1)$ & WUE $(\%)$ & EiC $(\mathrm{mol} \mathrm{m}-2 \mathrm{~s}-1)$ \\
\hline 0 & $146,05 \pm 18,20 \mathrm{a}$ & $11,03 \pm 0,75 \mathrm{a}$ & $1,38 \pm 0,33 \mathrm{~b}$ & $0,05 \pm 0,02 \mathrm{~b}$ \\
50 & $153,13 \pm 25,97 \mathrm{a}$ & $10,13 \pm 1,71 \mathrm{a}$ & $1,71 \pm 0,20 \mathrm{ab}$ & $0,06 \pm 0,01 \mathrm{~b}$ \\
100 & $180,13 \pm 29,73 \mathrm{a}$ & $11,35 \pm 3,02 \mathrm{a}$ & $2,26 \pm 0,14 \mathrm{a}$ & $0,11 \pm 0,02 \mathrm{a}$ \\
200 & $122,26 \pm 21,32 \mathrm{a}$ & $9,73 \pm 1,14 \mathrm{a}$ & $1,33 \pm 0,17 \mathrm{~b}$ & $0,04 \pm 0,01 \mathrm{~b}$ \\
400 & $148,10 \pm 24,28 \mathrm{a}$ & $10,10 \pm 2,28 \mathrm{a}$ & $1,46 \pm 0,53 \mathrm{~b}$ & $0,05 \pm 0,02 \mathrm{~b}$ \\
800 & $143,90 \pm 36,13 \mathrm{a}$ & $11,31 \pm 1,71 \mathrm{a}$ & $1,47 \pm 0,35 \mathrm{~b}$ & $0,05 \pm 0,02 \mathrm{~b}$ \\
1600 & $145,63 \pm 15,57 \mathrm{a}$ & $11,57 \pm 0,98 \mathrm{a}$ & $1,42 \pm 0,30 \mathrm{~b}$ & $0,06 \pm 0,02 \mathrm{~b}$ \\
\hline
\end{tabular}

\subsection{Análises bioquímicas}

Aos 69 DAT, ou seja, no início da fase reprodutiva do tomateiro, as atividades das enzimas SOD, GR, CAT e APX (Tabela 4) não foram afetadas pela aplicação de L-prolina em relação ao controle. Embora sem diferença estatística a aplicação exógena de L-prolina aumentou em 33,6 $\%, 4,9 \%, 15,5 \%$ e 23,4\% a atividade das enzimas SOD, GR, CAT e APX, respectivamente.

$\mathrm{O}$ conteúdo de peróxido de hidrogênio $\left(\mathrm{H}_{2} \mathrm{O}_{2}\right)$ nas folhas foi reduzido significativamente com a aplicação foliar de L-prolina independente da dose utilizada em relação ao controle (Tabela 5). Foi verificada uma redução significativa no conteúdo de MDA com a aplicação de $100 \mathrm{mg} / \mathrm{L}$ de L-prolina em relação ao controle e às doses de 200 e 800 mg/L (Tabela 5). 
Tabela 4. Atividade das enzimas antioxidantes superóxido dismutase (SOD), glutationa redutase (GR), catalase (CAT) e ascorbato peroxidase (APX), em folhas de tomateiro sob aplicação de L-prolina aos 69 DAT.

\begin{tabular}{ccccc}
\hline $\begin{array}{c}\text { Doses de L-prolina } \\
(\mathrm{mg} / \mathrm{L})\end{array}$ & $\begin{array}{c}\mathrm{SOD}(\mathrm{U} \mathrm{SOD} / \mathrm{mg} \text { de } \\
\text { proteína })\end{array}$ & $\begin{array}{c}\mathrm{GR}(\mu \mathrm{mol} / \mathrm{min} / \mathrm{mg} \\
\text { de proteína })\end{array}$ & $\begin{array}{c}\text { CAT }(\mu \mathrm{mol} / \mathrm{min} / \mathrm{mg} \\
\text { de proteína })\end{array}$ & $\begin{array}{c}\mathrm{APX}(\mathrm{nmol} / \mathrm{min} / \mathrm{mg} \\
\text { de proteína })\end{array}$ \\
\hline 0 & $10,28 \pm 1,87 \mathrm{a}$ & $0,8419 \pm 0,15 \mathrm{a}$ & $59,71 \pm 16,22 \mathrm{a}$ & $122,56 \pm 32,65 \mathrm{a}$ \\
50 & $11,09 \pm 1,87 \mathrm{a}$ & $0,9048 \pm 0,12 \mathrm{a}$ & $70,61 \pm 13,30 \mathrm{a}$ & $144,10 \pm 40,86 \mathrm{a}$ \\
100 & $13,83 \pm 7,73 \mathrm{a}$ & $0,7809 \pm 0,04 \mathrm{a}$ & $59,58 \pm 7,37 \mathrm{a}$ & $165,48 \pm 101,47 \mathrm{a}$ \\
200 & $17,00 \pm 6,24 \mathrm{a}$ & $0,9327 \pm 0,04 \mathrm{a}$ & $74,81 \pm 2,52 \mathrm{a}$ & $156,41 \pm 58,14 \mathrm{a}$ \\
400 & $14,73 \pm 3,96 \mathrm{a}$ & $0,9360 \pm 0,01 \mathrm{a}$ & $86,26 \pm 20,73 \mathrm{a}$ & $148,00 \pm 42,53 \mathrm{a}$ \\
800 & $13,93 \pm 6,32 \mathrm{a}$ & $0,8835 \pm 0,07 \mathrm{a}$ & $61,11 \pm 3,52 \mathrm{a}$ & $172,95 \pm 90,65 \mathrm{a}$ \\
1600 & $11,88 \pm 2,22 \mathrm{a}$ & $0,8611 \pm 0,04 \mathrm{a}$ & $61,41 \pm 6,38 \mathrm{a}$ & $121,03 \pm 19,66 \mathrm{a}$ \\
\hline
\end{tabular}

Tabela 5. Quantidade de indicadores de estresse, malonaldeído (MDA) e peróxido de hidrogênio $\left(\mathrm{H}_{2} \mathrm{O}_{2}\right)$ em folhas de tomateiro sob aplicação de L-prolina aos 69 DAT

\begin{tabular}{ccc}
\hline $\begin{array}{c}\text { Doses de L-prolina } \\
(\mathrm{mg} / \mathrm{L})\end{array}$ & $\begin{array}{c}\text { MDA } \\
\text { (mmol/g de matéria fresca) }\end{array}$ & $\begin{array}{c}\mathrm{H}_{2} \mathrm{O}_{2} \\
(\mathrm{mmol} / \mathrm{g} \text { de matéria fresca) }\end{array}$ \\
\hline 0 & $0,0239 \pm 0,000 \mathrm{ab}$ & $2,209 \pm 0,56 \mathrm{a}$ \\
50 & $0,0203 \pm 0,001 \mathrm{bc}$ & $1.372 \pm 0,61 \mathrm{~b}$ \\
100 & $0,0178 \pm 0,003 \mathrm{c}$ & $1,224 \pm 0,25 \mathrm{~b}$ \\
200 & $0,0231 \pm 0,002 \mathrm{ab}$ & $0,773 \pm 0,04 \mathrm{~b}$ \\
400 & $0,0212 \pm 0,001 \mathrm{abc}$ & $1,365 \pm 0,82 \mathrm{~b}$ \\
800 & $0,0248 \pm 0,001 \mathrm{a}$ & $0,816 \pm 0,05 \mathrm{~b}$ \\
1600 & $0,0199 \pm 0,002 \mathrm{bc}$ & $1,229 \pm 0,32 \mathrm{~b}$ \\
\hline
\end{tabular}

\subsection{Produtividade}

A produtividade total (PT) e a produtividade comercial (PC) aumentaram significativamente com a aplicação de 50 e $100 \mathrm{mg} / \mathrm{L}$ de L-prolina em relação ao controle (Tabela 6). As aplicações das doses de 200, 400, 800 e $1600 \mathrm{mg} / \mathrm{L}$ de L-prolina não elevaram significativamente a PT e a PC quando comparados com o controle.

O número de frutos comerciais (NC) aumentou 22,3\% e 19\% com a aplicação de $50 \mathrm{mg} / \mathrm{L}$ de L-prolina em relação ao controle e a maior dose desse aminoácido, respectivamente. A PNC, PP, PM e PG (Tabela 6), e o NT, NNC, NP, NM e NG (Tabela 7), por sua vez, não foram alterados pelos tratamentos.

Embora sem diferenças significativas, as aplicações de L-prolina nas doses de 50, 100, 200, 400, 800 e $1600 \mathrm{mg} / \mathrm{L}$ aumentaram a produtividade de frutos grandes (PG) em 100\%, 113\%, $127 \%$, 45\%, 100\% e 72\%, respectivamente, quando comparadas ao tratamento controle (Tabela 6). O mesmo pode ser visto em relação ao número de frutos grandes, onde as aplicações de 50, 
100, 200, 400, 800 e $1600 \mathrm{mg} / \mathrm{L}$ aumentaram em 109\%, 94\%, 124\%, 49\%, 94\% e 79\%, respectivamente, em relação ao controle (Tabela 7).

Tabela 6. Produtividade total de frutos (PT), Produtividade comercial de frutos (PC), Produtividade não comercial de frutos (PNC), Produtividade de frutos pequenos (PP), Produtividade de frutos médios (PM) e Produtividade de frutos grandes (PG) de tomates sob aplicação de L-prolina.

\begin{tabular}{ccccccc}
\hline $\begin{array}{c}\text { Doses de L- } \\
\text { prolina (mg/L) }\end{array}$ & PT (kg/planta) & PC (kg/planta) & PNC (kg/planta) & PP (kg/planta) & PM (kg/planta) & PG (kg/planta) \\
\hline 0 & $3,82 \pm 0,43 \mathrm{~b}$ & $3,62 \pm 0,36 \mathrm{~d}$ & $0,20 \pm 0,08 \mathrm{a}$ & $1,11 \pm 0,30 \mathrm{a}$ & $2,30 \pm 0,37 \mathrm{a}$ & $0,22 \pm 0,09 \mathrm{a}$ \\
50 & $4,76 \pm 0,69 \mathrm{a}$ & $4,45 \pm 0,47 \mathrm{a}$ & $0,19 \pm 0,05 \mathrm{a}$ & $1,56 \pm 0,21 \mathrm{a}$ & $2,45 \pm 0,32 \mathrm{a}$ & $0,44 \pm 0,13 \mathrm{a}$ \\
100 & $4,68 \pm 0,28 \mathrm{a}$ & $4,35 \pm 0,53 \mathrm{ab}$ & $0,33 \pm 0,13 \mathrm{a}$ & $1,36 \pm 0,42 \mathrm{a}$ & $2,54 \pm 0,27 \mathrm{a}$ & $0,47 \pm 0,28 \mathrm{a}$ \\
200 & $4,07 \pm 0,28 \mathrm{~b}$ & $3,92 \pm 0,29 \mathrm{bcd}$ & $0,15 \pm 0,04 \mathrm{a}$ & $0,92 \pm 0,18 \mathrm{a}$ & $2,50 \pm 0,23 \mathrm{a}$ & $0,50 \pm 0,29 \mathrm{a}$ \\
400 & $3,90 \pm 0,33 \mathrm{~b}$ & $3,77 \pm 0,34 \mathrm{~cd}$ & $0,13 \pm 0,03 \mathrm{a}$ & $1,09 \pm 0,06 \mathrm{a}$ & $2,36 \pm 0,20 \mathrm{a}$ & $0,32 \pm 0,21 \mathrm{a}$ \\
800 & $4,19 \pm 0,37 \mathrm{ab}$ & $4,02 \pm 0,28 \mathrm{abcd}$ & $0,18 \pm 0,12 \mathrm{a}$ & $1,22 \pm 0,27 \mathrm{a}$ & $2,36 \pm 0,23 \mathrm{a}$ & $0,44 \pm 0,11 \mathrm{a}$ \\
1600 & $3,96 \pm 0,26 \mathrm{~b}$ & $3,76 \pm 0,21 \mathrm{~cd}$ & $0,19 \pm 0,07 \mathrm{a}$ & $0,99 \pm 0,22 \mathrm{a}$ & $2,39 \pm 0,46 \mathrm{a}$ & $0,38 \pm 0,22 \mathrm{a}$ \\
\hline
\end{tabular}

Tabela 7. Número total de frutos (NT), número de frutos comerciais (NC), número de frutos não comerciais (NNC), número de frutos pequenos (NP), número de frutos médios (NM) e número de frutos grandes $(\mathrm{NG})$ de tomate sob aplicação de L-prolina.

\begin{tabular}{ccccccc}
\hline $\begin{array}{c}\text { Doses de L- } \\
\text { prolina } \\
(\mathrm{mg} / \mathrm{L})\end{array}$ & NT (n\%/planta) & NC (n\%/planta) & NNC (n\%/planta) & NP (n\%/planta) & NM (n\%/planta) & NG(n\%/planta) \\
\hline 0 & $46,33 \pm 6,43 \mathrm{a}$ & $39,67 \pm 4,16 \mathrm{~b}$ & $6,67 \pm 2,31 \mathrm{a}$ & $16,00 \pm 4,00 \mathrm{a}$ & $22,00 \pm 3,00 \mathrm{a}$ & $1,67 \pm 1,15 \mathrm{a}$ \\
50 & $52,67 \pm 1,15 \mathrm{a}$ & $48,50 \pm 5,07 \mathrm{a}$ & $6,67 \pm 2,08 \mathrm{a}$ & $22,50 \pm 3,32 \mathrm{a}$ & $22,75 \pm 3,30 \mathrm{a}$ & $3,50 \pm 1,00 \mathrm{a}$ \\
100 & $53,00 \pm 6,58 \mathrm{a}$ & $44,00 \pm 2,71 \mathrm{ab}$ & $8,75 \pm 4,35 \mathrm{a}$ & $17,50 \pm 2,89 \mathrm{a}$ & $23,50 \pm 2,52 \mathrm{a}$ & $3,25 \pm 1,71 \mathrm{a}$ \\
200 & $47,67 \pm 2,52 \mathrm{a}$ & $43,00 \pm 1,73 \mathrm{ab}$ & $5,25 \pm 1,50 \mathrm{a}$ & $14,25 \pm 2,50 \mathrm{a}$ & $24,33 \pm 3,06 \mathrm{a}$ & $3,75 \pm 2,22 \mathrm{a}$ \\
400 & $45,00 \pm 1,41 \mathrm{a}$ & $41,00 \pm 1,83 \mathrm{ab}$ & $4,50 \pm 1,73 \mathrm{a}$ & $16,25 \pm 1,50 \mathrm{a}$ & $22,50 \pm 1,29 \mathrm{a}$ & $2,50 \pm 1,29 \mathrm{a}$ \\
800 & $49,25 \pm 6,60 \mathrm{a}$ & $43,50 \pm 3,51 \mathrm{ab}$ & $5,75 \pm 3,30 \mathrm{a}$ & $18,00 \pm 3,46 \mathrm{a}$ & $22,25 \pm 2,22 \mathrm{a}$ & $3,25 \pm 0,50 \mathrm{a}$ \\
1600 & $46,25 \pm 3,77 \mathrm{a}$ & $40,75 \pm 1,89 \mathrm{~b}$ & $5,75 \pm 2,22 \mathrm{a}$ & $14,50 \pm 3,70 \mathrm{a}$ & $23,75 \pm 4,35 \mathrm{a}$ & $3,00 \pm 1,83 \mathrm{a}$ \\
\hline
\end{tabular}

\subsection{Características qualitativas}

Não houve diferença significativa entre os tratamentos para o teor de sólidos solúveis totais (SST, ${ }^{\circ}$ Brix) e de vitamina C em frutos de tomate (Tabela 8). A ATT, por sua vez, foi reduzida com a aplicação de L-prolina, independente da dose empregada. O contrário aconteceu para a relação SST/ATT, pois a aplicação exógena de L-prolina, aumentou o valor desse parâmetro em relação ao controle, independente da dose aplicada. 
Tabela 8. Teores de sólidos solúveis totais (SST, Brix), vitamina C (Vita C), acidez titulável (ATT) e Flavor (SST/ATT), em frutos de tomate sob aplicação de L-prolina aos 100 DAT.

\begin{tabular}{ccccc}
\hline $\begin{array}{c}\text { Doses de L-prolina } \\
(\mathrm{mg} / \mathrm{L})\end{array}$ & SST ( ${ }^{\circ}$ Brix) & $\begin{array}{c}\text { Vita C (g de vitamina } \\
\text { C/100g de polpa) }\end{array}$ & $\begin{array}{c}\text { ATT (\% de ácido } \\
\text { citrico) }\end{array}$ & SST/ATT \\
\hline 0 & $5,38 \pm 0,21 \mathrm{a}$ & $0,82 \pm 0,11 \mathrm{a}$ & $0,632 \pm 0,24 \mathrm{a}$ & $10,16 \pm 3,14 \mathrm{~b}$ \\
50 & $5,23 \pm 0,29 \mathrm{a}$ & $0,79 \pm 0,10 \mathrm{a}$ & $0,373 \pm 0,35 \mathrm{~b}$ & $14,07 \pm 1,21 \mathrm{a}$ \\
100 & $5,31 \pm 0,18 \mathrm{a}$ & $0,70 \pm 0,12 \mathrm{a}$ & $0,355 \pm 0,55 \mathrm{~b}$ & $15,24 \pm 2,83 \mathrm{a}$ \\
200 & $5,40 \pm 0,14 \mathrm{a}$ & $0,70 \pm 0,11 \mathrm{a}$ & $0,386 \pm 0,19 \mathrm{~b}$ & $13,53 \pm 0,27 \mathrm{a}$ \\
400 & $5,35 \pm 0,24 \mathrm{a}$ & $0,71 \pm 0,11 \mathrm{a}$ & $0,402 \pm 0,29 \mathrm{~b}$ & $13,39 \pm 1,21 \mathrm{a}$ \\
800 & $5,25 \pm 0,17 \mathrm{a}$ & $0,76 \pm 0,16 \mathrm{a}$ & $0,394 \pm 0,11 \mathrm{~b}$ & $13,34 \pm 0,26 \mathrm{a}$ \\
1600 & $5,40 \pm 0,26 \mathrm{a}$ & $0,73 \pm 0,12 \mathrm{a}$ & $0,399 \pm 0,22 \mathrm{~b}$ & $13,55 \pm 0,21 \mathrm{a}$ \\
\hline
\end{tabular}




\section{DISCUSSÃO}

Durante o período de cultivo do tomateiro, as temperaturas dentro da casa de vegetação foram maiores que as relatadas como ótimas por Alvarenga (2013) durante praticamente todo o ciclo (Figura 10). Dessa forma, pode-se afirmar a ocorrência de situações estressantes por altas temperaturas, que causam um desbalanço no metabolismo da planta, gerando EROs e consequentemente estresse oxidativo (TAIZ et al., 2017). Segundo Soliman et al. (2011), a exposição prolongada das plantas às temperaturas elevadas causam maiores danos no desenvolvimento das plantas do que temperaturas extremas por uma curta duração. Há uma relação intrínseca entre a intensidade e duração das altas temperaturas na interferência do metabolismo das plantas (WAHID et al., 2007).

O estresse por temperaturas altas causa redução drástica na germinação, no desenvolvimento das plantas, provoca queda de flores e abortamento de frutos, sendo o florescimento umas das fases mais sensíveis ao estresse térmico (FAHAD et al., 2017; PEET; SATO; GARDNER, 1998). Segundo Florido Bacallao \& Álvarez Gil (2015), a primeira resposta das plantas de tomate ao estresse por altas temperaturas é a redução do ciclo de todas as etapas de seu desenvolvimento, redução da fotossíntese e consequentemente do seu rendimento. Wise (2004) reporta que a máxima taxa fotossintética é observada por volta de $30{ }^{\circ} \mathrm{C}$ e acima dessa temperatura a taxa fotossintética é reduzida significativamente.

Para atenuar os efeitos negativos das temperaturas elevadas na produtividade e qualidade do tomateiro, o uso de bioestimulantes tem sido intensivamente empregado às lavouras em diferentes condições edafoclimáticas, dentre os quais os aminoácidos. Dentre os aminoácidos, a aplicação exógena de L-prolina tem mostrado efeitos positivos na regulação do estresse causado por fatores abióticos, sendo a L-prolina considerada um antioxidante auxiliando na eliminação das EROs e também modulando a homeostase através da ativação do metabolismo antioxidante (ASHRAF; FOOLAD, 2007).

Nesse estudo, o uso exógeno da L-prolina auxiliou no alívio do estresse térmico causado pelas altas temperaturas durante o ciclo do tomateiro. A aplicação de L-prolina nas doses de 50 e $100 \mathrm{mg} / \mathrm{L}$ elevou a produtividade total (PT) em 24,6\% e 22,5\%, a produtividade comercial (PC) em 22,9\% e 20,1\%, respectivamente (Tabela 6). A aplicação de $50 \mathrm{mg} / \mathrm{L}$ aumentou o número de frutos comerciais por planta (NC) em 22,2\% (Tabela 7).

A produtividade está diretamente relacionada ao período de florescimento e consequentemente a produção e viabilidade dos grãos de pólen (ABDELMAGEEDR; GRUDAZ, 2007). Esses autores, em estudo realizado com tomateiro cultivado em altas 
temperaturas, obtiveram menor número de grãos de pólen e massa de frutos produzidos por planta. Sato, Peet \& Thomas (2000), também em estudo realizado com tomates sob condições de estresse por temperaturas altas, verificaram que a frutificação e o número de grãos de pólen de diversos cultivares de tomate foram reduzidos pelas altas temperaturas $\left(32^{\circ} \mathrm{C}\right.$ diurna $/ 26^{\circ} \mathrm{C}$ noturna) quando comparadas às situações ótimas $\left(26^{\circ} \mathrm{C}\right.$ diurna $/ 22^{\circ} \mathrm{C}$ noturna). Em ambiente protegido, elevadas temperaturas durante o ciclo do tomateiro reduziram $38 \%$ a $68 \%$ o florescimento (ABDUL-BAKI, 1991). A baixa viabilidade e poder germinativo do grão de pólen em condições de altas temperaturas tem sido atribuído ao decréscimo da produtividade em espécies como o tomate (HASANUZZAMAN; NAHAR; FUJITA, 2009; PEET; SATO; GARDNER, 1998).

Segundo Zhou et al. (2017), a tolerância ao estresse térmico na fase da antese é a mais importante na determinação de alto rendimento. Porém, existem poucos estudos relacionando os efeitos iniciais e tardios das altas temperaturas na produtividade do tomateiro. Pressman et al. (2002), em estudo realizado com tomates em situações de altas temperaturas, constataram que o número de grão de pólen totais, número de grãos de pólen germinados e número de grão de pólen viáveis foram reduzidos significativamente com altas temperaturas, enquanto que o número de grãos de pólen inviáveis aumentou nessa condição de estresse. O aumento da inviabilidade de grãos de pólen sob altas temperaturas pode estar relacionado ao não acúmulo de amido nos grãos de pólen que está associado aos baixos níveis de açucares solúveis derivados da hidrólise do amido (PRESSMAN; PEET; PHARR, 2002).

O dano aos órgãos florais pelas altas temperaturas no tratamento controle influenciou a produtividade, visto que os mesmos são os mais afetados sob estresse térmico (WAHID et al., 2007). Outro fator que nos indica a extensão do dano provocado ao tomateiro é a significativa ocorrência de conteúdos elevados de peróxido de hidrogênio e malonaldeído no tratamento controle (sem aplicação de L-prolina) quando comparado aos tratamentos com doses de 50 e 100 mg/L de L-prolina (Tabela 5). Esses dois parâmetros nos mostram a ocorrência do estresse oxidativo (APEL; HIRT, 2004) e a possibilidade de degradação da membrana celular (SUZUKI; MITTLER, 2006). O aumento na produção de EROs está relacionado ao estresse por altas temperaturas no tratamento controle (MIT'TLER et al., 2004; WAHID et al., 2007).

O conteúdo de peróxido de hidrogênio nas folhas foi reduzido significativamente com a aplicação foliar de L-prolina independente da dose utilizada. Sánchez-Rodríguez et al. (2010) em estudo realizado com cinco cultivares de plantas de tomate sob condições de estresse hídrico, verificaram aumento no conteúdo de peroxido de hidrogênio nas plantas estressadas, resultado semelhante também encontrado por Mukherjee \& Choudhuri (1983) em plantas de feijão sob 
estresse hídrico. O uso da L-prolina exógena em plantas de uva sob estresse osmótico promoveu uma redução significativa no conteúdo de peróxido de hidrogênio quando comparado à plantas sem uso de L-prolina exógena (OZDEN; DEMIREL; KAHRAMAN, 2009). Em mudas de tamareira sob estresse por Cádmio (10 e $30 \mathrm{mg} / \mathrm{kg}$ de solo), a aplicação de L-prolina (20 mM) reduziu a quantidade de peróxido de hidrogênio formado nas folhas quando comparado aos tratamentos sem aplicação de L-prolina (ZOUARI et al., 2016). Esses resultados mostram a importância da L-prolina no alivio das injúrias causadas pelo estresse oxidativo.

Ashraf e Foolad (2007) reportam que a L-prolina pode atuar diretamente como um antioxidante para a eliminação das EROs ou também de maneira indireta para modular o equilíbrio através da ativação do metabolismo antioxidante. Nesse estudo, a primeira hipótese proposta por Ashraf e Foolad (2007) nos permite justificar a diminuição da quantidade de $\mathrm{H}_{2} \mathrm{O}_{2}$ pela ação da L-prolina (Tabela 5).

A quantidade de malonaldeído indica o grau de peroxidação lipídica das membranas (ZHENG et al., 2015). O conteúdo de MDA em plantas de Eurya emarginata aumentou sob estresse salino (200 mM de $\mathrm{NaCl}$ ) e diminuiu com a aplicação de $10 \mathrm{mM}$ de L-prolina e de 200 $\mathrm{mM}$ de $\mathrm{NaCl}$ na solução nutritiva, evidenciando o alivio do estresse pela L-prolina exógena (ZHENG et al., 2015). O conteúdo de MDA está relacionado também à produção de EROs e reflete a extensão do dano causado nas células (PANDA; KHAN, 2009), juntamente com o aumento verificado no conteúdo de peróxido causam impactos no desenvolvimento das plantas. Segundo Claussen (2005), a L-prolina atua na estabilização das membranas celulares, o que é demonstrado novamente com a redução nos teores de MDA quando aplicada na concentração de $100 \mathrm{mg} / \mathrm{L}$.

Aos 69 DAT, ou seja, no início da fase reprodutiva do tomateiro, a aplicação exógena de Lprolina aumentou em 33,6 \%, 4,9 \%, 15,5\% e 23,4\% a atividade das enzimas SOD, GR, CAT e APX, respectivamente. Resultados semelhantes foram encontrados por Zheng (2015), Islam (2009), Singh (2015) e Ben Ahmed et al. (2010),onde a aplicação exógena de L-prolina contribuiu para um aumento na atividade das enzimas do sistema antioxidante e atuou como soluto compatível e osmoprotetor (ASHRAF; FOOLAD, 2007; TAIZ et al., 2017).

A principal organela na geração de EROs são os cloroplastos (NOCTOR; REICHHELD; FOYER, 2017) e sua eliminação ocorre naturalmente no metabolismo celular. Porém, caso haja um estresse, ocorre um desbalanço no metabolismo que ocasiona a superprodução desses compostos tóxicos. O aparato fotossintético é um dos sistemas mais sensíveis em condições de temperaturas elevadas, onde a fotossíntese atinge seus valores máximos em torno de $30^{\circ} \mathrm{C}$, sendo que a cada grau adicionado, a assimilação de $\mathrm{CO}_{2}$ é reduzida (WISE et al., 2004). Um dos 
primeiros acontecimentos sob altas temperaturas na fotossíntese é a inativação (SALVUCCI; CRAFTS-BRANDNER, 2004; YAMORI et al., 2012) e redução da capacidade de regeneração (WISE et al., 2004) da enzima RUBISCO. Esses danos podem ser percebidos pelo cálculo da EiC (A/Ci), que mostra a eficiência do funcionamento da enzima Ribulose 1,5-difosfato carboxilase/oxigenase. Nesse estudo, a aplicação de $100 \mathrm{mg} / \mathrm{L}$ de L-prolina proporcionou aumento da EiC (Tabela 3), mostrando, assim, a promoção do ajuste e proteção do aparato fotossintético citado por Hayat et al. (2013).

Camejo et al. (2005) afirmam que o fotossistema II é muito responsivo à altas temperaturas, e sua atividade pode ser até cessada nesses casos. Similar a isso, pode-se afirmar que a eficiência do fotossistema II no tratamento com $100 \mathrm{mg} / \mathrm{L}$ de L-prolina aumentou 20\%, evidenciando novamente a proteção do sistema de fotossíntese proporcionada pela L-prolina (HAYAT et al., 2013).

A ausência de resposta da taxa fotossintética líquida, condutância estomática, concentração intercelular disponível de $\mathrm{CO}_{2}$ (Tabela 2), transporte aparente de elétrons e transpiração à aplicação de L-prolina também foi obtida por Camejo et al. (2005) em plantas de tomate sob estresse térmico. A explicação para ausência de resposta da condutância estomática está no fato da fotossíntese não ter sido limitada pelo fechamento estomático, mas sim pelos danos causados à Rubisco, que também ocorreu nesse estudo.

A L-prolina aumenta a atividade fotoquímica mediada pelo fotossistema II nas membranas do tilacóides e impede a perda da atividade fotoquímica em situações de estresse, protegendo as membranas contra a ação dos radicais livres (SIVAKUMAR; SHARMILA; PARDHA SARADHI, 2000), e dessa maneira também contribui para a redução da peroxidação lipídica (ALIA; PARDHA SARADHI; MOHANTY, 1991). Dessa forma, pode-se dizer que a L-prolina acumulada durante as condições de estresse atua como eliminadora de EROs e reguladora de $\mathrm{NAD}+$ e NADP+, mantendo os processos de respiração e fotossíntese (KAVI KISHOR et al., 2005).

A aplicação de $100 \mathrm{mg} / \mathrm{L}$ de L-prolina também elevou a WUE (A/E) quando comparada com o controle, não só pela redução da transpiração proporcionada pelo fechamento estomático, a fim de se evitar a perda de água, mas sim pela alta taxa fotossintética nesse tratamento. A aplicação de $10 \mathrm{mM}$ de L-prolina em folhas de plantas de berinjela cultivadas em solução salina aumentou a WUE em relação à aplicação de $20 \mathrm{mM}$ e o tratamento sem aplicação foliar (SHAHBAZ et al., 2013). No mesmo estudo não foram verificadas diferenças nos parâmetros de Gs, PhiPS2 e A com a aplicação de L-prolina. 
Mestre Ortuño (2014) não verificou diferenças nos parâmetros de A, Gs e E em plantas de tomate submetidas a estresse térmico $\left(35^{\circ} \mathrm{C}\right)$ quando comparadas às plantas não estressadas $\left(25^{\circ} \mathrm{C}\right)$. Ben Ahmed et al. (2010), em estudo realizado com plantas de oliveira sob estresse salino, com $100 \mathrm{mM}$ de $\mathrm{NaCl}$ na solução nutritiva, não verificaram diferenças nas taxas de fotossíntese líquida quando comparado com a aplicação de L-prolina nos teores de 25 e $50 \mathrm{mM}$.

A ausência de resposta da PT e a PC à aplicação de 200, 400, 800 e 1600 mg/L de L-prolina pode estar relacionada às altas concentrações de L-prolina na solução e metabolizada pelas plantas que inibiram a síntese de L-prolina no citoplasma, não resultando em ajuste osmótico (HEUER, 2003). Baixas concentrações de L-prolina exógena ativam a rota de síntese de Lprolina no citosol e dessa maneira regula o ajuste osmótico (HARE; CRESS; VAN STADEN, 1998; HAYAT et al., 2012) e Dawood et al. (2014).

Segundo Hayat (2012), baixas concentrações de L-prolina exógena protegem as plantas contra efeitos de salinidade, seca e altas temperaturas, enquanto que concentrações maiores implicam em efeitos tóxicos. Plantas de tomate cultivadas em solução salina e posteriormente tratadas com L-prolina exógena na solução, apresentaram efeitos deletérios chegando até morte celular quando usada a concentração de $10 \mathrm{mM}$ de L-prolina, efeito que não foi observado na concentração de 1 mM de L-prolina (HEUER, 2003).

O efeito do uso da L-prolina exógena no tomateiro não mostrou diferenças significativas no estado nutricional das plantas, que pôde ser observado na Tabela 1. O fornecimento de aminoácidos para as plantas não visa o suprimento nutricional de nitrogênio (CASTRO; CARVALHO, 2014). Dessa maneira não se deve esperar incremento nutricional com aplicações foliares de aminoácidos

Outro fator que pode ser levado em consideração é que até a data da coleta de folhas para análise nutricional, aos $50 \mathrm{DAT}$, não havia ocorrido muitos períodos com temperaturas elevadas que pudesse afetar a absorção de nutrientes pelas raízes. Nesses 50 dias, a temperatura média foi de $17,7^{\circ} \mathrm{C}$ e a média máxima foi $21,3^{\circ} \mathrm{C}$, não caracterizando estresse por altas temperaturas.

A aplicação exógena da L-prolina proporcionou efeito positivo na redução da acidez titulável dos frutos de tomate e, dessa maneira, também promoveu uma relação SST/ATT mais elevada (Tabela 8), o que proporcionou maior qualidade dos frutos (CHITARRA, M. I. F.; CHITARRA, 2005). Segundo esses autores, frutos com relação SST/ATT acima de 10 são mais saborosos, portanto, foi possível observar a elevação da qualidade dos frutos com a aplicação da L-prolina.

A redução da acidez titulável pela aplicação de aminoácidos já foi notada em uvas (ALBUQUERQUE; DANTAS, 2010) e em pêssegos (EL-RAZEK; SALEH, 2012). Albuquerque \& Dantas (2010) realizaram aplicações foliares de um composto de 20 aminoácidos, entre eles a 
L-prolina, em videiras, e constataram redução na acidez titulável dos frutos. Não houve alterações no SST dos frutos, o que também não foi verificado nesse estudo. El-Razek \& Saleh (2012) constataram redução na acidez titulável em pessegueiros submetidos à aplicações, de um composto de 16 aminoácidos, no solo e via foliar nas concentrações de 0,25 e $0,50 \%$. 


\section{CONCLUSÕES}

O uso exógeno de L-prolina proporcionou ativação do metabolismo antioxidante da planta e favoreceu a eliminação das EROs, proporcionando ao aparato fotossintético proteção para manutenção do metabolismo. Os efeitos positivos na fisiologia e metabolismo das plantas resultaram em aumento da produtividade e qualidade dos frutos de tomate.

A resposta positiva das plantas de tomate à aplicação exógena de L-prolina foi dependente da dose aplicada, porque as menores concentrações (50 e $100 \mathrm{mg} / \mathrm{L}$ ) foram mais eficientes na proteção das plantas contra o estresse térmico que resultaram em um aumento de $21,5 \%$ da produtividade comercial em relação ao controle. 


\section{REFERÊNCIAS}

ABDELMAGEEDR, A. H. A.; GRUDAZ, N. Influence of heat shock pretreatment on growth and deYelopment of tomatoes under controlled heat stress conditions. Journal of Applied Botany and Food Quality, v. 81, p. 26-28, 2007.

ABDUL-BAKI, A. A. Tolerance of Tomato Cultivars and Selected Germplasm to Heat Stress. J. Amer. Soc. Hort. Sci., v. 116, n. 6, p. 1113-1116, 1991.

AHMED, C. BEN et al. Changes in gas exchange, proline accumulation and antioxidative enzyme activities in three olive cultivars under contrasting water availability regimes. Environmental and Experimental Botany, v. 67, n. 2, p. 345-352, 2009.

ALBUQUERQUE, T. C. S. DE; DANTAS, B. F. Aplicação foliar de aminoácidos e a qualidade das uvas da cv. Benitaka. [s.l: s.n.]. Disponível em: <https://ainfo.cnptia.embrapa.br/digital/bitstream/item/38921/1/BPD-23-2010-ID-481.pdf $>$.

ALEXIEVA, V. et al. The effect of drought and ultraviolet radiation on growth and stress markers in pea and wheat. Plant, Cell and Environment, v. 24, n. 12, p. 1337-1344, 2001.

ALIA; PARDHA SARADHI, P.; MOHANTY, P. Proline enhances primary photochemical activities in isolated thylakoid membranes of brassica juncea by arresting photoinhibitory damage. BIOCHEMICAL AND BIOPHYSICAL RESEARCH COMMUNICATIONS, v. 181, n. 3, p. 1238-1244, 1991.

ALIA; SARADHI, P. P.; MOHANTY, P. Involvement of proline in protecting thylakoid membranes against free radical-induced photodamage. Journal of Photochemistry and Photobiology B: Biology, v. 38, n. 2-3, p. 253-257, 1997.

ALLEN, D. J. et al. Analysis of limitations to CO2 assimilation on exposure of leaves of two Brassica napus cultivars to UV-B. Plant, Cell and Environment, v. 20, p. 633-640, 1997.

ALSCHER, R. G.; DONAHUE, J. L.; CRAMER, C. L. Reactive oxygen species and antioxidants: Relationships in green cells. Physiologia Plantarum, v. 100, n. 2, p. 224-233, 1997. 
ALVARENGA, M. A. R. Tomate: produção em campo, casa de vegetação e hidroponia. 2. ed. Lavras: [s.n.].

APEL, K.; HIRT, H. REACTIVE OXYGEN SPECIES: Metabolism, Oxidative Stress, and Signal Transduction. Annual Review of Plant Biology, v. 55, n. 1, p. 373-399, 2004.

ARMENGAUD, P. et al. Transcriptional regulation of proline biosynthesis in Medicago truncatula reveals developmental and environmental specific features. Physiologia Plantarum, v. 120, n. 3, p. 442-450, 2004.

ASADA, K. Production and Scavenging of Reactive Oxygen Species in Chloroplasts and Their Functions. Plant Physiology, v. 141, n. 2, p. 391-396, 2006.

ASHRAF, M. Biotechnological approach of improving plant salt tolerance using antioxidants as markers. Biotechnology Advances, v. 27, n. 1, p. 84-93, 2009.

ASHRAF, M.; FOOLAD, M. R. Roles of glycine betaine and proline in improving plant abiotic stress resistance. Environmental and Experimental Botany, v. 59, n. 2, p. 206-216, 2007.

ASHRAF, M.; SAEED, M. M.; QURESHI, M. J. Tolerance to high temperature in cotton (gossypium hirsutum L.) at initial growth stages. Environmental and Experimental Botany, v. 34, n. 3, p. 275-283, 1994.

AZEVEDO, R. A. et al. Response of antioxidant enzymes to transfer from elevated carbon dioxide to air and ozone fumigation, in the leaves and roots of wild-type and a catalase-deficient mutant of barley. Physiologia Plantarum, v. 104, n. 2, p. 280-292, 1998.

BEN AHMED, C. et al. Exogenous proline effects on photosynthetic performance and antioxidant defense system of young olive tree. Journal of Agricultural and Food Chemistry, v. 58, n. 7, p. 4216-4222, 2010.

BEN AHMED, C.; BEN ROUINA, B.; BOUKHRIS, M. Effects of water deficit on olive trees cv. Chemlali under field conditions in arid region in Tunisia. Scientia Horticulturae, v. 113, n. 3, p. 267-277, 2007.

BOLWELL, G. P. et al. The apoplastic oxidative burst in response to biotic stress in plants: A three-component system. Journal of Experimental Botany, v. 53, n. 372, p. 1367-1376, 2002. 
BRADFORD, M. M. A rapid and sensitive method for the quantitation of microgram quantities of protein utilizing the principle of protein-dye binding. Analytical Biochemistry, v. 72, n. 1-2, p. 248-254, 1976.

CAMEJO, D. et al. High temperature effects on photosynthetic activity of two tomato cultivars with different heat susceptibility. Journal of Plant Physiology, v. 162, n. 3, p. 281-289, 2005.

CARVALHO, C.R.L.; MANTOVANI, D.M.B.; CARVALHO, P. R. N. .; MORAES, R. M. . Análises químicas de alimentosCampinasInstituto de Tecnologia de Alimentos, , 1990.

CASTRO, P. R. DE C. E; CARVAlHO, M. E. A. Aminoácidos e suas aplicações na agricultura. Piracicaba: [s.n.].

CHARTZOULAKIS, $\mathrm{K}$. et al. Effects of $\mathrm{NaCl}$ salinity on growth, ion content and $\mathrm{CO} 2$ assimilation rate of six olive cultivars. Scientia Horticulturae, v. 96, n. 1-4, p. 235-247, 2002.

CHAVES, M. M.; FLEXAS, J.; PINHEIRO, C. Photosynthesis under drought and salt stress: Regulation mechanisms from whole plant to cell. Annals of Botany, v. 103, n. 4, p. 551-560, 2009.

CHITARRA, M. I. F.; CHITARRA, A. B. Pós Colheita de Frutas e Hortaliças. 2. ed. Lavras: [s.n.].

CLAUSSEN, W. Proline as a measure of stress in tomato plants. Plant Science, v. 168, n. 1, p. 241-248, 2005.

DAWOOD, M. G. et al. The changes induced in the physiological, biochemical and anatomical characteristics of Vicia faba by the exogenous application of proline under seawater stress. South African Journal of Botany, v. 93, p. 54-63, 2014.

EL-RAZEK, E. A.; SALEH, M. M. S. Improve Productivity and Fruit Quality of Florida Prince Peach Trees Using Foliar and Soil Applications of Amino Acids. Middle-East Journal of Scientific Research, v. 12, n. 8, p. 1165-1172, 2012.

FAHAD, S. et al. Crop Production under Drought and Heat Stress: Plant Responses and Management Options. Frontiers in Plant Science, v. 8, n. June, p. 1-16, 2017. 
FAROOQ, M. et al. Plant drought stress : effects, mechanisms and management. Agronomy for Sustainable Development, Springer Verlag/EDP Sciences/INRA, v. 29, n. 1, p. 185-212, 2009.

FLORIDO BACALLAO, M.; ÁLVAREZ GIL, M. ASPECTOS RELACIONADOS CON EL ESTRÉS DE CALOR EN TOMATE ( Solanum lycopersicum L .). Cultivos Tropicales, v. 36, p. 77-95, 2015.

FUMIS, T. DE F.; PEDRAS, J. F. Variação nos níveis de prolina, diamina e poliaminas em cultivares de trigo submetidas a déficits hídricos. Pesquisa Agropecuária Brasileira, v. 37, n. 4, p. 449-453, 2002.

GAGNEUL, D. et al. A Reassessment of the Function of the So-Called Compatible Solutes in the Halophytic Plumbaginaceae Limonium latifolium. Plant Physiology, v. 144, n. 3, p. 1598$1611,2007$.

GIANNOPOLITIS, C. N.; RIES, S. K. Superoxide Dismutases: I. Occurrence in Higher Plants. Plant Physiology, v. 59, n. 2, p. 309-314, 1977.

GOMES-JUNIOR, R. A. et al. Antioxidant metabolism of coffee cell suspension cultures in response to cadmium. Chemosphere, v. 65, n. 8, p. 1330-1337, 2006.

HAMILTON, E. W. Mitochondrial Adaptations to NaCl. Complex I Is Protected by AntiOxidants and Small Heat Shock Proteins, Whereas Complex II Is Protected by Proline and Betaine. Plant Physiology, v. 126, n. 3, p. 1266-1274, 2001.

HARE, P. D.; CRESS, W. A. Metabolic implications of stress-induced proline accumulation in plants. Plant Growth Regulation, v. 21, n. 2, p. 79-102, 1997.

HARE, P. D.; CRESS, W. A.; VAN STADEN, J. Dissecting the roles of osmolyte accumulation during stress. Plant, Cell and Environment, v. 21, n. 6, p. 535-553, 1998.

HASANUZZAMAN, M.; NAHAR, K.; FUJITA, M. Extreme Temperature Responses , Oxidative Stress and Antioxidant Defense in Plants. Abiotic Stress - Plant Responses and Applications in Agriculture, p. 169-205, 2009. 
HAYAT, S. et al. Role of proline under changing environments: A review. Plant Signaling and Behavior, v. 7, n. 11, p. 1456-1466, 2012.

HAYAT, S. et al. Proline enhances antioxidative enzyme activity, photosynthesis and yield of Cicer arietinum L. exposed to cadmium stress. Acta Botanica Croatica, v. 72, n. 2, p. 323-335, 2013.

HEATH, R. L.; PACKER, L. Photoperoxidation in isolated chloroplasts. Archives of Biochemistry and Biophysics, v. 125, n. 1, p. 189-198, 1968.

HEUER, B. Influence of exogenous application of proline and glycinebetaine on growth of saltstressed tomato plants. Plant Science, v. 165, n. 4, p. 693-699, 2003.

HONG, Z. et al. Removal of Feedback Inhibition of $\Delta^{1}$-Pyrroline-5-Carboxylate Synthetase Results in Increased Proline Accumulation and Protection of Plants from Osmotic Stress. Plant Physiology, v. 122, n. 4, p. 1129-1136, 2000.

HOQUE, M. A. et al. Proline and glycinebetaine enhance antioxidant defense and methylglyoxal detoxification systems and reduce $\mathrm{NaCl}$-induced damage in cultured tobacco cells. Journal of Plant Physiology, v. 165, n. 8, p. 813-824, 2008.

IBGE. Informações sobre culturas temporárias: Quantidade produzida, área plantada: tomate, 2017. Disponível em: <htps://sidra.ibge.gov.br/tabela/1618>. Acesso em: 4 jun. 2018.

ISLAM, M. M. et al. Exogenous proline and glycinebetaine increase antioxidant enzyme activities and confer tolerance to cadmium stress in cultured tobacco cells. Journal of Plant Physiology, v. 166, n. 15, p. 1587-1597, 2009.

JACOBSON, M. D. Reactive oxygen species and programmed cell death. Trends in biochemical sciences, v. 21, n. 3, p. 83-86, 1996.

KAVI KISHOR, P. B. et al. Reguation of proline biosynthesis, degradation, uptake and transport in higher plants: its implications in plant growth and abiotic stress tolerance. Current Science, v. 88, n. May 2014, p. 424-438, 2005. 
KHEDR, A. H. A. et al. Proline induces the expression of salt-stress-responsive proteins and may improve the adaptation of Pancratium maritimum L. to salt-stress. Journal of Experimental Botany, v. 54, n. 392, p. 2553-2562, 2003.

KIM, H.-S. et al. Chapter 2 Reactive Oxygen Species: Regulation of Plant Growth and Development. Advances in Botanical Research, v. 52, p. 25-46, 1 jan. 2009.

KOURIL, R. et al. High-temperature induced chlorophyll fluorescence rise in plants at 40-50 C: experimental and theoretical approach. Photosynthesis Research, v. 81, p. 49-66, 2004.

KRAUS, T. E.; MCKERSIE, B. D.; FLETCHER, R. A. Paclobutrazol-induced Tolerance of Wheat Leaves to Paraquat May Involve Increased Antioxidant Enzyme Activity. Journal of Plant Physiology, v. 145, n. 4, p. 570-576, 1995.

LOBELL, D. B.; WOSCHLENKER, F.; COSTA-ROBERTS, J. Climate Trends and Global Crop Production Since 1980. Science, v. 333, p. 616-620, 2011.

MÄKELÄ, P. et al. Effect of glycinebetaine on chloroplast ultrastructure, chlorophyll and protein content, and RuBPCO activities in tomato grown under drought or salinity. Biologia Plantarum, v. 43, n. 3, p. 471-475, 2000.

MALAVOLTA, E.; VITTI, G. C.; OLIVEIRA, S. A. Avaliação do estado nutricional das plantas: princípios e aplicações. 2. ed. Piracicaba: Associação Brasileira para Pesquisa da Potassa e do Fosfato, 1997.

MEDEIROS, D. B. et al. Physiological and biochemical responses to drought stress in Barbados cherry. Brazilian Society of Plant Physiology, v. 24, n. 3, p. 181-192, 2012.

MILLER, G. et al. Unraveling $\Delta$-pyrroline-5-carboxylate-proline cycle in plants by uncoupled expression of proline oxidation enzymes. Journal of Biological Chemistry, v. 284, n. 39, p. 26482-26492, 2009.

MITTLER, R. et al. Reactive oxygen gene network of plants. Trends in Plant Science, v. 9, n. 10, p. 490-498, 2004.

MOLDES, C. A. et al. Biochemical responses of glyphosate resistant and susceptible soybean plants exposed to glyphosate. Acta Physiologiae Plantarum, v. 30, n. 4, p. 469-479, 2008. 
MOLINARI, H. B. C. Expressão estresse-induzida do gene P5CS em plantas transgênicas de cana-de-açúcar submetidas ao déficit hídrico. 2006.

MUKHERJEE, S. P.; CHOUDHURI, M. A. Implications of water stress-induced changes in the levels of endogenous ascorbic acid and hydrogen peroxide in Vigna seedlings. Physiologia Plantarum, v. 58, n. 2, p. 166-170, 1983.

MUNNS, R.; TESTER, M. Mechanisms of Salinity Tolerance. Annual Review of Plant Biology, v. 59, n. 1, p. 651-681, 2008.

NAGARAJAN, S.; NAGARAJAN, S. Abiotic Tolerance and Crop Improvement BT - Abiotic Stress Adaptation in Plants: Physiological, Molecular and Genomic Foundation. In: PAREEK, A.; SOPORY, S. K.; BOHNERT, H. J. (Eds.) . Dordrecht: Springer Netherlands, 2010. p. 1-11.

NAIDU, B. P. et al. Amino acid and glycine betaine accumulation in cold-stressed wheat seedlings. Phytochemistry, v. 30, n. 2, p. 407-409, 1991.

NAKANO, Y.; ASADA, K. Hydrogen Peroxide is Scavenged by Ascorbate-specific Peroxidase in Spinach Chloroplasts. Plant and Cell Physiology, v. 22, n. February, p. 867-880, 1981.

NOCTOR, G.; REICHHELD, J. P.; FOYER, C. H. ROS-related redox regulation and signaling in plants. Seminars in Cell and Developmental Biology, v. 80, p. 3-12, 2017.

ORTUÑO, T. M. Respuesta de las plantas de tomate a la combinación de salinidad y altas temperaturas. [s.l: s.n.].

OZDEN, M.; DEMIREL, U.; KAHRAMAN, A. Effects of proline on antioxidant system in leaves of grapevine (Vitis vinifera L.) exposed to oxidative stress by H2O2. Scientia Horticulturae, v. 119, n. 2, p. 163-168, 2009.

PANDA, S. K.; KHAN, M. H. Growth, oxidative damage and antioxidant responses in greengram (Vigna radiata L.) under short-term salinity stress and its recovery. Journal of Agronomy and Crop Science, v. 195, n. 6, p. 442-454, 2009.

PEET, M. M.; SATO, S.; GARDNER, R. G. Comparing heat stress effects on male-fertile and male-sterile tomatoes. Plant, Cell and Environment, v. 21, p. 225-231, 1998. 
PRESSMAN, E.; PEET, M. M.; PHARR, D. M. The effect of heat stress on tomato pollen characteristics is associated with changes in carbohydrate concentration in the developing anthers. Annals of Botany, v. 90, p. 631-636, 2002.

\section{Programa Brasileiro para Modernização da Horticultura - Normas de Classificação do}

Tomate. São PauloCentro de Qualidade em Horticultura - CQH/CEAGESP (CQH. Documentos, 26), , 2003. Disponível em: <http://www.ceagesp.gov.br/wpcontent/uploads/2015/07/tomate.pdf>

RAJENDRAKUMAR, C. S. V; SURYANARAYANA, T.; REDDY, A. R. DNA helix destabilization by proline and betaine: Possible role in the salinity tolerance process. FEBS Letters, v. 410, n. 2-3, p. 201-205, 1997.

RIVERO, R. M.; RUIZ, J. M.; ROMERO, L. M. Importance of N source on heat stress tolerance due to the accumulation of proline and quaternary ammonium compounds in tomato plants. Plant Biology, v. 6, n. 6, p. 702-707, 2004.

ROOSENS, N. H. et al. Isolation of the ornithine-delta-aminotransferase cDNA and effect of salt stress on its expression in Arabidopsis thaliana. Plant Physiology, v. 117, n. 1, p. 263-271, 1998.

SALVUCCI, M. E.; CRAFTS-BRANDNER, S. J. Inhibition of photosynthesis by heat stress: The activation state of Rubisco as a limiting factor in photosynthesis. Physiologia Plantarum, v. 120, n. 2, p. 179-186, 2004.

SÁNCHEZ-RODRÍGUEZ, E. et al. Genotypic differences in some physiological parameters symptomatic for oxidative stress under moderate drought in tomato plants. Plant Science, v. 178 , n. 1, p. 30-40, 2010.

SARADHI, P. P.; ALIA, S. A.; PRASAD, K. V. S. K. Proline accumulates in plants exposed to UV radiation and protects them against UV induced peroxidation. Biochemical And Biophysical Research Communications, v. 209, n. 1, p. 1-5, 1995.

SATO, S.; PEET, M. M.; THOMAS, J. F. Physiological factors limit fruit set of tomato (Lycopersicon esculentum Mill.) under chronic, mild heat stress. Plant, Cell and Environment, v. 23, p. 719-726, 2000. 
SHAHBAZ, M. et al. Does proline application ameliorate adverse effects of salt stress on growth, ions and photosynthetic ability of eggplant (Solanum melongena L.)? Scientia Horticulturae, v. 164, p. 507-511, 2013.

SILVA, F. G. DA et al. Trocas gasosas e fluorescência da clorofila em plantas de berinjela sob lâminas de irrigação. Revista Brasileira de Engenharia Agricola e Ambiental, v. 19, n. 10, p. 946-952, 2015.

SILVA, V. A. et al. Resposta fisiológica de clone de café Conilon sensível à deficiência hídrica enxertado em porta-enxerto tolerante. Pesquisa Agropecuaria Brasileira, v. 45, n. 5, p. $457-$ 464, 2010.

SINGH, M. et al. Exogenous proline application ameliorates toxic effects of arsenate in Solanum melongena L. seedlings. Ecotoxicology and Environmental Safety, v. 117, 2015.

SIVAKUMAR, P.; SHARMILA, P.; PARDHA SARADHI, P. Proline alleviates salt-stressinduced enhancement in ribulose-1,5-bisphosphate oxygenase activity. Biochemical and Biophysical Research Communications, v. 279, n. 2, p. 512-515, 2000.

SOLIMAN, W. S. et al. Oxidative stress and physiological damage under prolonged heat stress in C3 grass Lolium perenne. Grassland Science, v. 57, n. 2, p. 101-106, 2011.

SOLIMAN, W. S. et al. Heat tolerance and suppression of oxidative stress: Comparative analysis of 25 cultivars of the C 3 grass Lolium perenne. Environmental and Experimental Botany, v. 78, p. 10-17, 2012.

SUNG, D. Y. et al. Acquired tolerance to temperature extremes. Trends in Plant Science, v. 8, n. 4, p. 179-187, 2003.

SUZUKI, N.; MITTLER, R. Reactive oxygen species and temperature stresses: A delicate balance between signalling and destruction. Physiologia Plantarum, v. 126, p. 41-51, 2006.

SZABADOS, L.; SAVOURÉ, A. Proline: a multifunctional amino acid. Trends in Plant Science, v. 15, n. 2, p. 89-97, 2010.

TAIZ, L. et al. Fisiologia e Desenvolvimento Vegetal. 6 ${ }^{a}$ ed. 2017. 
TATAGIBA, S. D. et al. Limitações fotossintéticas em folhas de plantas de tomateiro submetidas a crescentes concentrações salinas. Engenharia na Agricultura, v. 22, n. 2, p. 138-149, 2013.

WAHID, A. et al. Heat tolerance in plants: An overview. Environmental and Experimental Botany, v. 61, n. 3, p. 199-223, 2007.

WISE, R. R. et al. Electron transport is the functional limitation of photosynthesis in field-grown Pima cotton plants at high temperature. Plant, Cell and Environment, v. 27, n. 6, p. 717-724, 2004.

XUE, X.; LIU, A.; HUA, X. Proline accumulation and transcriptional regulation of proline biosynthesis and degradation in Brassica napus. BMB reports, v. 42, p. 28-34, 2009.

YAMORI, W. et al. Rubisco activase is a key regulator of non-steady-state photosynthesis at any leaf temperature and, to a lesser extent, of steady-state photosynthesis at high temperature. Plant Journal, v. 71, n. 6, p. 871-880, 2012.

YANG, S. L.; LAN, S. S.; GONG, M. Hydrogen peroxide-induced proline and metabolic pathway of its accumulation in maize seedlings. Journal of Plant Physiology, v. 166, n. 15, p. 1694-1699, 2009.

ZHENG, J. L. et al. Exogenous proline reduces $\mathrm{NaCl}$-induced damage by mediating ionic and osmotic adjustment and enhancing antioxidant defense in Eurya emarginata. Acta Physiologiae Plantarum, v. 37, n. 9, p. 1-10, 2015.

ZHOU, R. et al. Physiological Response to Heat Stress During Seedling and Anthesis Stage in Tomato Genotypes Differing in Heat Tolerance. Journal of Agronomy and Crop Science, v. 203, n. 1, p. 68-80, 2017.

ZOUARI, M. et al. Exogenous proline mediates alleviation of cadmium stress by promoting photosynthetic activity, water status and antioxidative enzymes activities of young date palm (Phoenix dactylifera L.). Ecotoxicology and Environmental Safety, v. 128, n. November, p. 100-108, 2016. 